\title{
The arts and finance
}

Citation for published version (APA):

Pownall, R. A. J. (2016). The arts and finance: Inaugural address given in shortened form by Rachel A.J. Pownall. Maastricht University. https://doi.org/10.26481/spe.20160318rp

Document status and date:

Published: 18/03/2016

DOI:

10.26481/spe.20160318rp

Document Version:

Publisher's PDF, also known as Version of record

\section{Please check the document version of this publication:}

- A submitted manuscript is the version of the article upon submission and before peer-review. There can be important differences between the submitted version and the official published version of record.

People interested in the research are advised to contact the author for the final version of the publication, or visit the DOI to the publisher's website.

- The final author version and the galley proof are versions of the publication after peer review.

- The final published version features the final layout of the paper including the volume, issue and page numbers.

Link to publication

\footnotetext{
General rights rights.

- You may freely distribute the URL identifying the publication in the public portal. please follow below link for the End User Agreement:

www.umlib.nl/taverne-license

Take down policy

If you believe that this document breaches copyright please contact us at:

repository@maastrichtuniversity.nl

providing details and we will investigate your claim.
}

Copyright and moral rights for the publications made accessible in the public portal are retained by the authors and/or other copyright owners and it is a condition of accessing publications that users recognise and abide by the legal requirements associated with these

- Users may download and print one copy of any publication from the public portal for the purpose of private study or research.

- You may not further distribute the material or use it for any profit-making activity or commercial gain

If the publication is distributed under the terms of Article $25 \mathrm{fa}$ of the Dutch Copyright Act, indicated by the "Taverne" license above, 


\section{The arts and finance}

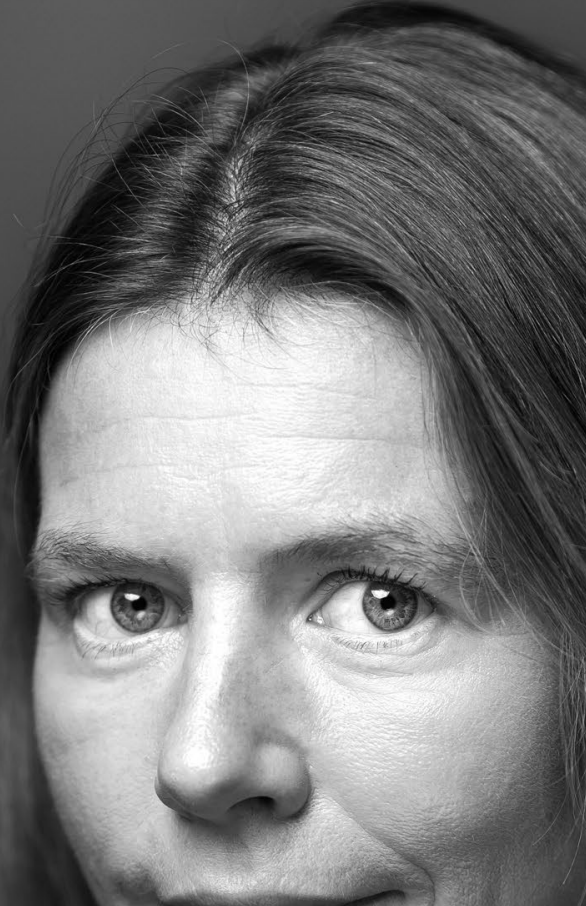

Inaugural address given in shortened form by Rachel A.J. Pownall

Maastricht University

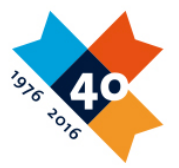

MACCH 
Rachel A. J. Pownall Rachel A. J. Pownall is Professor of Arts Finance at Maastricht University, and the first global Professor of Art Finance and Museum Management at TIAS School for Business and Society. She is founder and Academic Director of the Master in Art Finance program at TIAS, Tilburg University, together with Fudan University, China and the Van Gogh Museum, Amsterdam. She also founded and teaches on the two Masterclasses: Art Finance, and Art Business and Collections Management. Rachel has taught for Sotheby's Institute of Art, and has lectured at Christies Education, and the Royal Academy of Arts and regularly consults for practitioners. She has provided economic advice since 200I for the Fine Art Fund, London, UK, and her Fine Art Indexes constitute to the Mei \& Moses ${ }^{\mathrm{TM}}$ All Art Indexes for Beautiful Asset Advisors LLC.

She is also a GSBE research fellow at Maastricht University and her research interests broadly cover the realm of understanding investor behaviour. She has a particular focus on art markets and assets with an emotional attachment. She is interested in the behavioural issues of how emotions and psychology influence individuals' financial decision-making involving risk. This includes understanding about the non-pecuniary benefits from investment, such as how aesthetic, environmental, and emotional values, and the influence of how individual aspects of status and relative wellbeing influence investment decisions. Her passion for research stems from a belief that through a better understanding of how individuals make risky decisions and incorporating social, cultural as well as financial returns to investment into decision-making will help promote a society that makes more sustainable investment decisions in future.

Her work has appeared in international peer reviewed journals like the European Economic Review, Journal of International Money and Finance, and the Journal of Economic Behavior and Organization. She serves on the editorial boards of the Journal of International Money and Finance, the Journal of Behavioral and Experimental Economics, the International Review of Financial Analysis, and Financial Research Letters. 


\title{
The arts and finance
}

\author{
Rachel A. J. Pownall
}

\section{Inaugural address}

given in shortened form upon the public acceptance of the appointment as professor of Arts Finance at Maastricht University on Friday I $8^{\text {th }}$ March 2016 by Rachel A. J. Pownall. 
(C) Rachel A. J. Pownall, 2016

ISBN: 978-94-6I67-272-8

All rights reserved. This publication is protected by copyright, and permission must be obtained from the publisher prior to any reproduction, storage in a retrieval system, or transmission in any form or by any means, electronic, mechanical, photocopying, recording or otherwise.

www.tilburguniversity.edu 


\section{The arts and finance}

'I never come upon any of my discoveries through the process of rational thinking' - Albert Einstein 
Abstract

Abstract

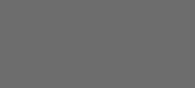

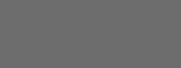

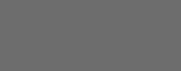

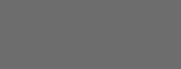

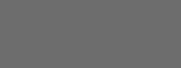

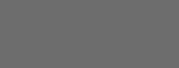
(2)

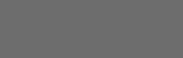

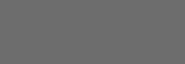

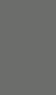

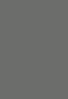




\section{Introduction}

As a professor in art and finance I am proud to be the first holder of this chair globally. I am interested in the intersection of these two disciplines, 'The Arts', and 'Finance'. The arts represent an outlet of expression. Expression is influenced by culture. The arts help to change culture. The culture of finance is in need of change and how we go about this change is the essence of my talk today.

\section{Contribution}

My research in financial markets focuses on behavioural issues and making decisions under risk. I am particularly interested in the non-financial aspects of investment. These matter to people when buying financial products. For example, the aesthetic and emotional aspects of a product or service, the financial wellbeing of an individual, or how environmentally friendly of socially responsible the good is? All these aspects influence investment decisions. They all have value. In my research I have used quantitative models to determine what these values are. From fine art to violins I have created price indexes from the late I8th century until the current time. This helps us understand how the market values for these assets move over time.

\section{Goal}

So what is my goal? The focus in finance only on financial returns has brought with it tremendous economic prosperity, but also instability and uncertainty, lack of autonomy and irresponsibility. Emphasising non-financial aspects and softer metrics such as trust, connections with people, and communities, will help us as a society to focus not just on economic values, but also on social and cultural values. I want individuals and institutions to make more sustainable long-term investment decisions that benefit both business and society. In this address I will outline why finance needs the arts and how this will bring finance to the arts.

\section{Impact}

As scholars in this field, we are under the obligation to make a change. My focus is on changing the attitude towards how we value the cultural and societal impact from our financial decisions. The arts can help us with this challenge. This inadvertently will transform the perspective of our decisionmaking to the longer term and help to secure a fairer, freer, more ethical society that we can live in; a society that I can cherish. 
'Art is meant to disturb. Science reassures.' 'Art is meant to disturb. Science reassures.'

\section{Introduction}


The arts represent an outlet of expression that is usually influenced by culture and which in turn helps to change culture. As such the arts are a physical manifestation of the internal creative impulse ${ }^{\mathrm{I}}$.

In finance we focus less on the creative impulse. Even on the heated trading floor, we assume that traders act in a rational manner and execute trades as information changes.

They evaluate the price at which they currently want to trade (buy or sell) using the financial information available to them at the time. If there is perfect information available to all, then the economists' rational expectations probabilistic model implies efficient markets.

Financial markets are inherently efficient in the theoretical sense of the word, with future prices hard to forecast, and hence returns largely unpredictable. Classical economic theory describes decision making in line with the reasoned economic man where it is reasonable to only take information that the market values into consideration when pricing assets.

As participants on financial markets, it is us, who define which aspects the market values. Currently that focus is on shareholder value. Unless we put a price on non-shareholding stakeholders, such as the environment, the social welfare of employees, or on other aspects of businesses, then the market will not either. The domination of institutional investors in the arena, who focus on the single metric of shareholder return, means that it should therefore not come as a surprise to us that the market does not currently value many non-financial aspects from investing. Unless, we start to place more intrinsic value on non-shareholding stakeholders, and non-financial aspects, we cannot expect the market to.

Because these factors are not currently priced does not mean that we cannot motivate investors to value them ${ }^{2}$. Investors and consumers must be

\footnotetext{
I This is the definition of the arts according to the Oxford English Dictionary.

2 In a similar manner roughly a third of the food in European agriculture production is wasted. Supermarkets claim that consumers do not want to buy products such as imperfect looking vegetables, and in addition throw out a large proportion of their weekly food shop. To value the external cost to society from this enormous waste, requires educating consumers. Motivating consumers to change their shopping habits through education is a preferred means than having to impose costs (taxes) to value the externalities.
} 
educated. The free market is the efficient mechanism through which demand and supply is brought together. If the market fails to do its job, it is because of the preferences of the market participants and not because of the market itself. If intrinsic motivation alone is not enough to change behaviour then other forms of extrinsic motivation are required. Reward (and penalty) through the price mechanism is one means with which we can incentivise individuals to change behaviour. Other ways we can extrinsically motivate individuals are through tapping into behavioural aspects such as praise, competition, fame, and prestige. Recent research in neurofinance aims at understanding the reward mechanism in the brain with respect to risk. Our brains react to many types of rewards, not just financial.

The aim of this inaugural address is to show that by bringing culture, change and creativity to finance, in the form of making investment decisions and in providing finance, we can further our understanding and thinking as a society to bring the interests and wants of individual investors in line with funding and financing areas of the economy which have traditionally been underfunded or even excluded.

This is partially due to the externalities being mispriced, (or sometimes not priced at all). We need to take into account the non-financial aspects of investing. It is also due to further market failures, lack of information and ignorance, mistrust, differing subjective beliefs, and the myopic behaviour of investors. I believe that turning to the arts helps us think about these externalities, and in realising the challenge of bringing innovation and creativity to finance.

Learning to value emotional, social, creative and expressive values of investments is key in this context to developing valuation models which will encourage investors and financers to focus on long term sustainable investments, such as innovative enterprises, socially responsible investments, and funding the structural development of the creative economy. The art markets is one avenue in which these values can be analysed using empirical price data over time.

My focus today is that through such 'artistic reasoning' we can as a society move more in this direction, to bring art and finance to the next generation. 
I can only hope to form a small part in that process. I will outline my research agenda, and also address the question of how and why to finance the arts, and in doing so, also reflect upon why finance needs the arts?

I hope to inspire you. 


\section{Market rationale

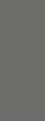

'We know the price of everything and the value of nothing'
- Oscar Wilde

'We know the price of everything and the value of nothing'
- Oscar Wilde

(n)

年

(n)


Financial innovation of products and services, as it is manifested in economics, helps resolve the problems of bringing together those willing to lend with a surplus of funds (supply) with those in need of funds (demand) to finance projects through the mechanism of financial markets. Funds provide investment opportunities to finance projects, traditionally in the form of loans, bonds, equity, and various other financial structures, and contracts, to shift risk to those who are willing to finance risky projects and investments, in the hope of some future reward. Access to efficient capital markets has been the pre-cursor to the vast growth in the global economy.

To secure this high level of economic production and subsequent growth it has however, come at a cost. As economists we understand that scarce resources all have an opportunity cost. The mechanism of the free market puts a price on goods and services, but this does not necessarily equate to 'value'. In finance we aim to value the streams of revenues and costs that we can quantify and measure. To this end we use market prices that we interchange with and equate to values. The focus is on the financial benefits and the financial costs. Measured in terms of monetary values we use the financial return and the financial risk associated with investment projects.

Friedman (I962) famously stated that the 'sole social responsibility of business is to increase its profits'. In a world without market and government failures this advice would indeed be recommended. Corporations have followed this mantra and economic growth has also come at the greater cost to society as a whole. To maintain the competitive levels of production globally, it has been necessary to ignore vital questions having to do with the manufacturing process, the physical and economic health of human beings, and at the expense of our natural world. These are social and public costs for the current generation and undoubtedly for generations to come.

Traditionally we have chosen to externalise these costs to society as a whole, to the non-shareholding stakeholders. We pay the price for what is termed 'externalities' through greater tax burdens, for example for health, social-welfare and the environment. Our implicit contract when requiring businesses to act according to the disciplines of free market economics is that when the market fails to allocate resources efficiently the government will intervene successfully in the market to redistribute. For example, when corporations get too big or 
too powerful, only then should we use the legal framework to reduce monopoly powers. This is one of various guises of the free market failing, and we term 'a market inefficiency'.

One of the most pressing needs is in the provision of public goods: goods that provide a greater value to society to the benefit of all. The provision of public goods, such as national defense, clean air, culture and heritage, if left to the free market alone, generally do not receive sufficient, or adequate, funding. This market failure arises due to the ability of individuals to benefit without sufficient contribution (free riders), and due to non-rivalry (my use does not reduce your use) and non-excludability (you can consume the good anyway) Public goods therefore suffer from being underprovided in the free market. The large positive externalities that they offer society are incorrectly priced. The price mechanism undervalues their contribution to society.

The competitiveness of the global economy has resulted in governments worldwide not always having the means, resources, and ability to correct for these types of market failures adequately. The huge demand on government budgets for public goods requires trade-offs having to be made between quasi-public goods, such as education, research, defense, healthcare and the arts. Particularly when the payoff structure from the costs and benefits are not appropriated at the same time (asset-liability management). And governments are not well incentivised to act in the public's interest (principal-agent problems $s^{4}$ ) insufficient alignment of pay, lobbying power of large institutions, as well as large distortions due to asymmetric information and knowledge between governments, business, and the electorate. In essence - the presence of further market failures. We cannot expect the government to provide policy that corrects for all these market failures in the system.

There is also the long-term cost to society. Another major market failure of the financial system is the inability of the market to value the long-term. This is not a fault of the market system itself (it is rather like a workman blaming his tools). It is rather the inability of players on financial markets to correctly value the long-term. This market failure should be recognised and long-term

3 Pure private goods rival each other and are excludable, quasi-public goods are partially rival or excludable.

4 Jensen and Meckling (I976). 
behaviour should be promoted and encouraged. Agriculture and fast fashion are eminent examples of this. Cheap food and produce at the detriment of the ecosystem and the environment ${ }^{5}$.

A further consequence from the current financial system is the long term under investment into people and society; and a failure to incentivise employees to engage in 'softer' activities that maintain long-term value such as mentoring and recruiting, and fostering trust and communities. These values have also been externalised in various forms: research, innovation, education and training. Maintaining short-term profit at the long-term expense of a healthy and happy workforce. Companies adopting non-financial mechanisms for key performance indicators are more likely to have happier and more motivated employees. This may be captured by higher productivity, but it may also be penalised by shareholders in equity markets for not focusing on measurable financial profits and thus shareholder value. It also comes at the potential additional cost of greater bureaucracy and lost time. The price mechanism currently undervalues the employee as a stakeholder and it is borne as a societal cost.

Compare this to cooperatives or to privately owned companies where the employee has a higher stakeholder value. Externalising communities is less of an issue when companies are not publically owned by shareholders, but rather are privately owned or exist as co-operatives. The value of team work, shared experience, communities, can be more easily managed with long term goals, than the short-termism which companies trading on the stock market typical face.

The growth in information and technology facilitated the approach of performance and data driven compensation models. The single metric, where money as a financial reward is used as an incentive to lubricates the cogs of the economy. This can result in individuals and departments working competitively against each other. Often with a lack of responsibility towards clients and services provided.

5 As HRH Prince Charles points out in his address on the long-term sustainability and agriculture in 2OII in Washington. 
In the organisational culture literature, leadership and management studies have focused more recently on how to intrinsically motivate employees. Treating employees as people and communities of teams, and the use of soft metrics rather than solely performance driven on the single financial metric ${ }^{6}$.

In the wake of the global financial crises, where trust was lost, and the prolonged global recession, today, as a society we are engaging with and encompassing the more complex questions of value. Major questions arise. How to overcome this burden on society, which brings enormous issues and problems? How to focus on non-shareholder stakeholder values? How do we remain competitive in a world where these costs can be undermined by less stringent laws and regulation? These are challenges facing us a society.

How can companies encourage shareholders to focus on longer -term behaviour and non-financial values? Institutional investors state their fiduciary responsibility is to focus on the single metric of financial returns as their legal obligation. Yet, the combined principles of prudence and a duty of loyalty, should take precedence (see Ransome and Sampford, 20I3). We require the focus to be broader than the single metric of financial returns alone.

Free markets and the reliance on the price mechanism as a means to allocate resources has brought with it the growth and great prosperity since the industrial revolution. We certainly want to maintain our reliance on the efficient mechanism of the market to price according to what we value. However, in so doing, we require market participants to value the societal costs, which are currently being externalised. Until shareholders are able to put a value on these costs we cannot expect that the market will value these costs.

Empirical research provides evidence that the market only prices in positive externalities when they bring with them a financial benefit. For example because it brings greater productivity, higher efficiency, or lowers costs. Termed 'doing well by doing good', research by Derwall et al. (2005), Kempf and Osthoff (2008), Statman and Glushkov (2009), Eichholtz et al. (2010) and Edmans (20II), all provide positive evidence for the enhancement of corporate value from policies directed towards particular elements of corporate

6 HBR article November (2015) Martha Samuelson. 
responsibility; for example, strong environmental responsibility, green office buildings, and high employee satisfaction. If such corporate policies result in non-shareholder stakeholders benefitting whilst shareholders also benefit there is a win-win situation. We are learning to value these factors, and potential changes in these factors, through metrics such as the KLD metrics on ESG (Environmental Social and Governmental factors).

There is also a mass of other studies, which do not show evidence of the market valuing corporate social activities. For example, funds of corporations, which contain companies, which screen for positive socially responsible behaviour, underperform. When 'doing good comes at a cost', there are negative externalities, manifesting themselves as a trade-off across stakeholders. In our current system the value to the shareholder takes a precedent and the external cost to society requires strong government policy to fund undervalued external costs. Unless tackled by strong government policy, when a trade-off exists between the non-shareholding stakeholders and the shareholders, then economic growth comes at a cost to society.

Furthermore, we should also value the positive externalities to society. A healthier workforce reduces stress related costs in healthcare. Physical and psychological wellbeing improves productivity. Community and social activities improve a sense of community and trust. Access to the arts has an impact on social and cultural aspects of life. There are also important benefits to overall health and lifestyle; reduction in stress; a reduction in the slowdown of our cognitive abilities; increasing creativity and innovation.

Besides just measuring economic value we can account for these social and cultural values. As a society we can help ourselves by investing into companies, people, communities, that generate long-term gains. The community spirit that is borne from cultural and social events such as the positive spirit emulating from shared sporting spirit, music concerts, gigs, cultural activities and museums, exhibitions, should all receive additional funding to reflect the positive externalities that they provide to society.

Moreover, these intangible aspects all help in building trust and a sense of community. As non-financial benefits to society, they are currently underpriced by the market mechanism and public funding does not satisfactorily price their true value to society. 
Rather than the current approach to public funding (fire-fighting new flames), to maintain the threats of short-term unemployment, terrorism, infrastructure, healthcare and education, to tolerable levels, these should be areas with much greater funding. This requires a much more structured approach to long-term funding. A more strategic approach to fighting the fires within our society, and building the infrastructure, will also result in a knock-on multiplier effect to society. It requires that the externalities are truly internalised.

Ideally we would like to make use of the efficient mechanism of the market to redistribute and value external costs and benefits. How can this be achieved? A classical approach thus prices these externalities at source. By providing a mechanism for companies to also value the internal costs that they equate to the negative externalities that they exert on stakeholders other than the shareholders. Thus internalising the true costs of production. For example including the positive side effects of health and wellbeing in human resource management and the cost of carbon as environmental costs, or the lower labour costs behind fast fashion.

Bringing costs in line with the true costs to society, and to nature and reaping benefits from other dimensions than just financial alone would result in a more efficient mechanism to price and allocate funds globally. As the Nobel Laureate Ronald Coase (1960) points out in discussing the social cost of production, this requires restraining the party who is creating the externalities through property rights. However, lack of exclusivity and universality of many of these externalities require us to seek alternative mechanisms to price the social and cultural value, rather than rely on the market pricing value correctly and government policy.

As a society, we have become so detached from the process with which money is made, clothes are produced, food is grown. Bringing awareness to the value-chain of how our goods and services come to fruition is a crucial part of being able to bring prices in line with values.

How we manage to bring prices in line with true costs and values will determine how successful we will be in the future and how well we progress in our transition as a cultured society. Here, culture goes beyond society as a whole, and importantly also addresses the issues in corporate culture. 
Corporate culture will only change if investors, lenders, and consumers drive that change. There is plenty of evidence that individual investors and consumers do care and want to know. We need to facilitate that knowledge. The answer is in educating societies. The process can be demand driven, rather than supply driven. Corporations will supply products that the consumer demands. By creating more awareness about the non-financial aspects of products and services the investor is able to value both positive and negative externalities. Making shareholders aware of the value-chain and thus the non-financial values is the key to this process. Reducing asymmetric information requires a fully educated investor and consumer. We can move towards this. Governments can provide platforms for this. Citizens (and shareholders) need to be empowered. Through crowd-funding investors are driving financial innovation in capital markets for providing funding to creative enterprises, but issues of risk and trust pertain.

The arts give us a perspective with which we can face this challenge. The arts provide us with a different lens through which we can view the world. Through which we can disrupt, disturb and change the way we look and think about the world. 'Whilst art is meant to disturb, science reassures' to quote Georges Braque. The recent Ai Wei Wei exhibition at the Royal Academy of Arts, in London, highlights the costs to Chinese society from the rapid expansion and production for consumers worldwide. I do not advocate to prevent, nor to protect, our economy from the availability of these products, just that when we consume them we consider the value-chain and the external costs and benefits on society from consuming these goods and services. The arts help us as a society to take the time to consider, and to value the non-financial aspects of goods and services. Brings trust, community, and purpose. These aspects will help in the provision of a society that is sustainable in the long term. Re-orientating ourselves towards this type of thinking and approach, will maintain competitiveness in the economy, whilst balancing our current desire for short-term profits. Investment is more than just financial reward it requires a long-term strategic aim.

My research aims at trying to help reconcile these differences. Understanding and adjusting financial returns for financial risk, but also for non-financial rewards, and also for non-financial risks is a major part of my research. It also requires bringing investor preferences in line with the attributes of the assets in which one is investing, is the mechanism with which we can start to do this. It is to this aspect, which I now turn. 


\section{Refreshing rationality}

'There is more reason in your body than in your best wisdom'.
- Nietzshce 
Under the strict assumptions of rational choice investors' behaviour may be considered at times irrational. People appear to be both risk averse and yet also gamble. A sufficient number of people shun investments into companies whose profits rely on consumers' dependence towards addictive substances such as tobacco and alcohol. Is it really irrational to donate financial wealth to philanthropic causes? Although this type of investor behaviour is outside the doctrine of rational choice behaviour, rational expectations, and also standard finance theory, can we really consider it as irrational? Behavioural finance brings psychology to standard finance to help explain why investors behave as they do.

As Meir Statman describes in his forthcoming book, investors are just "normal', they have hopes and fears and wants. They are not irrational. The cognitive errors that investors have been described as making are not unreasonable, and can in the most part be reasoned and rationalised by relaxing or altering the assumptions of the reasoned economic man, homo-economicus?.

How we make choices behind risky decisions is central in understanding how investors make decisions, and why they demand and supply the financial assets that they do.

Rational decision-making has its origins in Bernoulli (I738) where individuals maximise the expected value of a utility function. He recognised that attitudes to risk differ across individuals, and he advocated the use of the logarithmic utility function. Log utility captures the idea of 'a small increase in wealth being inversely proportionate to the quantity of goods previously possessed'. Classically, preferences are state-independent and given equal weighting.

Famous paradoxes, such as Allais (1953) and Ellsberg (1963) highlighted that individuals behave in a different manner than they should under the normative theory of expected utility. A subsequent large body of behavioural studies describes how individuals actually appear to make decisions. It is far beyond the scope of this talk to discuss the variety of developments in this area, but

7 It is possible to rationalise much of the observed 'irrational' behaviour that stems from people not conforming to the assumptions of the homo-economicus. Only insanity is viewed as what cannot be rationalised, and therefore interesting to study from a medical and neuroscientific perspective. As Einstein quipped, insanity is doing the same things over and over again, and expecting different results. 
generally, these various alternative approaches relax the classical assumptions behind rational normative utility. For example allowing for alternative representations of utility. Classically, utility represented a measure of pleasure or happiness, and although the most common means to measure value is through prices (profits and returns), we should not overlook that the overall purpose is to capture a broader concept of utility. Failure to equate value with prices indicates that there are other values that may give utility. Decisions are not just self-interested, but utility is gained from altruism, thus social and cultural values too.

Utility is all encompassing and captures the effects of beliefs, values, risk attitudes, probabilities and state-dependence. Aspects such as knowledge, friendship, health are difficult to measure, thus it is not unsurprising that these aspects were largely ignored in early models, particularly in models for representative agents, and when considering decisions between risky assets.

Traditionally, in a financial setting, we have therefore focused on income or wealth as a measure for utility (Friedman and Savage I964). Investments are chosen according to modern portfolio theory (Markowitz, I964) those that yield the highest expected return for the least amount of risk. Investors behave as Friedman suggests. Expected to maximise profits using risk-adjusted financial returns. Financial risk is typically measured as the volatility of the expected return distribution (an assumption that we will discuss in more detail later).

When making these types of decisions involving risky assets the approach has therefore been for investors to foremost maximise utility by maximising financial returns. The philosophy behind this process of focusing on the single metric of financial returns is that investors can themselves choose how to spend their financial rewards, if and how they choose to donate their profits to a particular cause, rather than institutional investors choosing on their behalf. This mechanism, as Professor Statman states is 'akin to suggesting to an Orthodox Jew that he forgo kosher food for cheaper non-kosher food and donate the savings to his synagogue.'

When the process of investment itself involves and influences society, and other non-shareholding stakeholders, then we need to rethink our models to 
include these considerations. The underlying point is that the value-chain matters. Investors do care about how the returns to investment are being made.

One prominent piece of empirical evidence in the literature from Hong and Kacperczyk (2009) find the relative out-performance of 'sin stocks'. Stocks of corporations whose core business is within certain taboo industries such as alcohol, defense, and the tobacco industries. These results pertain across countries depending on the social norms of the countries investigated. Another perspective on these results is that investors obtain a premium from the disutility of holding the stocks of socially 'irresponsible' firms. This thinking echoes that there is (dis)utility from non-financial aspects of investments. In particular investors do not want to make high financial returns at any cost.

In a paper with a co-author, (Borgers and Pownall (2013)) we value this tradeoff using data on Dutch households. In a second paper with a different coauthor, (De Silva and Pownall (2014)), we find evidence that the educated, and environmentally conscience, particularly females, are more willing to give up financial return for social values.

For those with a social conscience, utility is clearly derived from non-financial or non-pecuniary aspects of investing. It is not simply a case of financial reward at all cost. People care about the social and cultural impact of their investments, and not just the financial economic impact.

Utilitarian benefits of expressive and emotional benefits also play a role. These can be attained from high social status, from playing and winning (trading as entertainment), and from adhering to our values, from for example living in a fair and just world. Rather than just a strict focus on financial risks and returns, if we also consider non-financial returns, we can correct for the fact that the market does not price in the social and cultural values to the investor when choosing what to invest in.

In the extreme case of charitable giving, the utility derived from a donation must be solely altruistic. It can be considered the warm glow from helping others, see Alchian, I953, and Bollen (2007). And philanthropy and charitable giving is on the rise globally. So is social impact investing; the name dedicated to investing in organisations and corporations that also aim to measure performance on social as well as economic grounds. 
Rather than being taxed heavily the rich (and moreover the super-rich) want to take the redistribution of income into their own hands. If possible, 'doing well whilst doing good', we also observe that investors are willing to do good whilst giving up some financial return. This implies that the utility from the social and cultural return from the investment sufficiently compensates for accepting a lower financial return.

I am keen to further develop my research along these lines. Determining exactly how these preferences influence decision making over the short and long-term is of benefit to our understanding about the process of motivating investors to value externalities.

Foundations and endowments used to help finance science, medicine, education, human services, and for the arts and culture, are ways for affluent entrepreneurs to contribute to an improving society. The non-pecuniary reward is attained in the form of the good that they provide, but also can come in their own self-recognition, the social status, from belonging to the top numbers of charitable donors, the name plaque above the auditorium door of the Business School who accepts your pledge. This is not cynicism but rather recognising that human beings also want to be recognised by contributions over and above just financial ones. Motivating investors to find support for these types of investments requires understanding the reward patterns of investors. This will mobilise resources to the quasi-public goods discussed above and currently undervalued and thus underfunded within the economy. Rather than creating an uncompetitive playing field, the market mechanism will reallocate resources to those with the highest economic value plus crucially social and cultural value, and not just to those with the greatest financial reward.

Allowing for other types of rewards, non-financial rewards, allows us to explain why in practice the descriptive relation between financial risk and returns does not hold in practice. There is a gap between theory and reality. Assets can be classed in terms of their characteristics, and also by the amount of affect that they offer investors. A positive value chain can lead to an asset being rich in affect. Culture and the arts are all examples of goods that are extremely affect-rich. 
Affect-rich goods offer much more than just economic or financial returns to investors and collectors. They can offer an emotional or aesthetic return, in the form of pleasure, or enjoyment, that inspires and helps creativity and innovation. They can alleviate and reduce stress, and increase health and wellbeing. Moreover they may offer many positive external effects to society as a whole. As discussed in the previous chapter, these externalities need to be priced in. They will then receive the funding and allocation that they deserve.

Establishing that assets with positive elements or aspects generate a non-pecuniary return, explains why they may only require a lower rate of expected financial return to encourage investors to invest in them. I discuss this in de Roon et al. (2008) and in Dempster (2013) in a chapter on why Boutique art funds are an attractive vehicle of investment for investors and collectors in the art market. In the research I elucidate how assets such as art have particular qualities which distinguish them from many other goods and commodities. I provide a framework in which the emotional or affective value of such assets can be understood and appreciated.

Here we have discussed extensions of the expected utility framework in terms of utility and how various aspects of reward (not just financial) pertain to utility. It is highly rational to gain utility from aspects other than only financial reward. It is important that these values are also priced in to society and economics so that we maximise returns with respect to value and not just to prices. It helps to bring empirical behavioural findings in line with classical theory. Rationalising individuals' behaviour within the bounds of assumptions, rather than terming behaviour as irrational, would be a more refreshing way to consider rationality and rational markets.

There are various other extensions to expected utility theory, in the form of how risks are measured and interpreted, to which I would like to turn your attention. 
Subjectivity and

uncertainty

'We do not see things as they are, we see them as we are.'

- Anaïs Nin 
The Nobel Prize in 20I4 was given jointly to Eugene Fama and Robert Shiller for their work on financial markets. Although there appears to be a substantial gap between the theory behind the efficient market hypothesis of Fama and the behviour of investors as empirically observed by Shiller ${ }^{8}$, these at first diametrically opposing views can be reconciled. So how?

Simply put, it's a matter of subjectivity and uncertainty, which influences the intensity with which events are experienced and the frequencies with which events happen.

Theories and models are abstractions of reality - simplifications where parsimony is preferred. The efficient market hypothesis of Eugene Fama is just that. Based on rational expectations, where expectations are unknowns, but that are known. Forecasting and predictions about the future use probabilities that are known. Chance or randomness is what we most often refer to as risk ${ }^{9}$.

In reality there is also uncertainty around these probabilities ${ }^{10}$. The unknowns are $u n k n o w n^{\text {II }}$. Lack of information, ignorance and mistrust also pertain to this type of uncertainty. We seek to reduce this type of uncertainty and in Professor Fama's theory of efficient markets, markets fully reflect information, so this form of uncertainty is reduced completely. It is only the fundamentals that should matter.

In reality we do not just face risk as we adhere to it in finance, but also face these uncertainties; and we are averse to risks Ellsberg (I96I) Savage (I972) and Epstein (I999). Allowing models to include subjectivity and uncertainty explains this gap between theory and practice. Although the market appears to function efficiently (in as far as it follows a random walk and forecasting is inherently impossible) this occurs when considering the notion of risk, rather than both risk and uncertainty.

8 Paul de Grauwe tweeted: 'Nobel Prize for Fama who led millions to believe financial markets are efficient and for Shiller who showed opposite. What a contradiction.'

9 Risk in this sense is correctly termed aleatory uncertainty.

Io Also termed epistemic uncertainty or ambiguity.

II Knight (I92I) defines risk as a gamble with known distribution and uncertainty as a gamble with unknown distribution. 
Both risks and uncertainties are key to the functioning of financial markets. The uncertainty of future movements in asset prices is what drives trading on financial markets. Differences in subjective opinion about expectations and beliefs manifest themselves in a continual change in the demand for and supply of financial products and services. For equity, the current stock price therefore reflects the potential capital gain and dividend stream for the financial asset. Trading requires as a pre-requisite that individuals' beliefs on future expected values are heterogeneous. When trading, uncertainty surrounding the unknown still remains. It is subjective. It is this ambiguity or uncertainty can also be incorporated into expected utility theory.

Alternative extensions to expected utility theory allow for different interpretations of probability. For example, subjective expectations, Knightian uncertainty surrounding potential unforeseen errors, conditional probabilities, robust optimisation, and Bayesian updating are all extensions of expected utility theory. Rather than weighting expected utility as equal prospects, probabilities can have assigned different weightings. The most common weighting form is the non-linear S-shaped value function that gives a high weighting to extreme events and also to losses.

Behavioural applications from the psychology literature address how models can be applied to incorporate investor behaviour. The field has grown enormously over the last I5 years. The most prolifient behavioural models used have been prospect theory (Kahenman and Tversky (I979)) and versions of ambiguity aversion. Both hugely popular in advancing the field of behavioural finance and the body of finance literature.

In Prospect theory, the notion that decisions are made relative to a reference point, that losses are weighed more heavily than gains (loss aversion); and the use of a value function can be imposed to transform probabilities. The weighting captures the sensitivity with which probabilities diminish over the function. Tversky and Kahneman's cumulative prospect theory (1992) is an attractive way to capture risk and uncertainty. They propose that when people evaluate risk, they transform objective probabilities using a weighting function. The weighting function is subjective, and thus has the attractive feature that one can include for weightings according to tastes and preferences. 
Extreme events carry a greater weight in accordance with the preference of their outcome. Lotteries will make you rich and potentially change your life, as could very risky stocks (i.e. stocks as lotteries). In Barberis and Huang (2008), the authors use this approach to reveal how skewness is priced. Further empirical evidence from the finance literature, shows that returns from IPOs, distressed stocks, high volatility stocks, and overpriced out-of-the money options, are well explained using models incorporating probability weighting functions. See Barberis (2013) for more discussion on this.

It is reassuring to think that by the use of subjectivity and uncertainty weighted probabilities (either attributed to the known risks themselves or to ambiguous uncertainties) we can reconcile behavioural finance with classical expected utility theory. The two Nobel Laureates, Eugene Fama and Robert Shiller's insightful work in these two extreme positions of this debate are not juxtaposed, but rather can be reconciled through considering alternative assumptions in expected utility theory.

The research that I have worked on in this area is forthcoming. One area is on frames of reference. With Meir Statman and Kees Koedijk we focus on aspirations and financial wellbeing, Koedijk et al. (2015). Where we build on Prospect Theory since individuals are risk averse in the domain of high financial wellbeing relative to others and risk seeking in the domain of losses, where financial wellbeing is lower than others. Using empirical data from Dutch households we find this effect stronger for individuals who are more status seeking and competitive. This research ties in with the findings of Kahneman and Deaton (20I0) on subjective and emotional wellbeing and household income. They find high income does not buy happiness, but helps towards life satisfaction. We find risk-taking dependent on relative financial wellbeing and not on income. In Tzerki et al. (20I5) we find evidence that reference-points change. In Graddy et al. paper (2015) we find evidence of loss-aversion in the art market, which increases over time.

Another particular interesting area to consider, pertaining to the uncertainty of the unknowns is trust. Trust reflects the uncertainty about the future behaviour of the trustee. This could be the financial advisor, the investment manager, the bank, the government, or the dealer, the auction house. The level of trust is also subjective and also pertains to epistemic uncertainty. 
Guiso et al. (2008) show that trust acts as a hurdle to investing in the stock market. Trustworthiness changes over time. Trust is gained with reputations and with relationships. In the wake of the financial crises, how we develop trust is of vital importance. It is highly related to society and culture, and although difficult to measure, it will determine the extent to which we as a society evolve our financial services industry. Banking and funding mechanisms with crowdfunding almost entirely prevalent online raises the aspects of security and trust management. The mechanisms to ensure the self-regulation of markets, particularly in the arts, is currently at play. How the future for banking, loans, particularly in the area of arts and culture is an interesting area for further research.

We can also consider alternative measures and estimates of risk in extending expected utility theory. For example, low morale can be considered a threat hence the prospect of lower productivity can be measured in terms of risk. In the psychological models of Lopes (1987), she uses weighted probabilities to capture hope and fear ${ }^{12}$. This links to the work by Loewenstein et al. (200I) on risk-as-feelings and Rottenstrich and Hsee (2004) on affective psychology. We have the tendency to attribute less risk to positive characteristics and prospects and attach more risk to negative characteristics and prospects. Since we observe the subjective distribution, this can be transformed to the objective distribution using an implied weighting function. Hence from using empirical observations of the risk-return relation of various assets, we can estimate the implied value of these subjective preferences.

This may differ across asset types. For example emotionally loaded assets, such as those with high social and cultural impact will require a larger value in the weighting function, than assets that only offer investors a financial return. This provides us with a framework with which we can understand the extent to which individuals subjectively value social and cultural aspects over and above the financial value, estimated from market prices. I think it is compelling to refer to the extent of this effect from various assets as 'affect richness'.

I2 In an earlier version of the Aspirations paper we included the Lopes model for hope and fear, by using probability weightings. 
We can value the non-pecuniary benefits which assets offer investors using probability weighting functions to transform empirically observed financial return distributions, see Pownall (2012).

Likewise, individuals will also differ in the amount by which they themselves are affected by the affect richness of the asset. Under rational expectations, an agent would not put any value on the valence of an asset. That is the intrinsic attractiveness or aversiveness that a particular asset has.

Less work has looked at the ideas behind alternative measures for rewards or returns in terms of lowering or heightening risk. This is a compelling idea that would benefit us all in the finance and economics literature for society at large. It brings together research in cognitive psychology with behavioural finance, fitting well within the framework of subjective expected utility theory.

I believe that this approach provides a framework with which can begin to establish prices which reflect values. It also offers a unifying way to think about a number of phenomena. Weighting through the value-function gives us a tool with which we can transform objectively measured financial risk and rewards back to the more holistic risk and reward framework.

Affect richness helps explain the low average returns on affect rich assets with a social and cultural attachment. Affect valence incorporates heterogeneous preferences to how individuals wish to value products and services with a social or cultural component.

In this manner, the aesthetic enjoyment from owning an affect rich asset, such as an artwork can also be considered a pleasure and can be considered as offsetting the risk of a fall in the resale price. It is interesting to note what I have referred to as 'value-attribution-bias' (Dempster, 20I4) if owners of art tend to attribute art price appreciation to investor potential but can withstand depreciation because of affective value. While we would all like to attribute price increases to having made a successful investment, it may be easier to admit that one bought an artwork or case of wine for its aesthetic beauty or for its taste when the price drops. 
Affective processes and neuroscience teaches us that there is an important distinction between reasoning and emotions. Reasoning is a cognitive process controlled by the cerebral cortex in the higher brain area, whereas emotions are affective processes controlled by the amygdala in the lower brain area. Affective processes drive our decision-making and learning about them will help further our understanding of how to motivate business and society to also value these non-pecuniary characteristics.

Antonio Damasio (I995) argues that feelings generated by the body are an essential element of rational thought. 'Rationality requires feeling, and feeling requires the body'. This process requires that reasoned decision-making requires both body and mind. Similarly art and science are intertwined, to which we now turn. 
The arts and finance 3I 


\section{'Pricing the Priceless'
- William D. Grampp \\ 'Pricing the Priceless'
- William D. Grampp

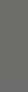 \\ Arts markets \\ theng

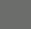

(n)

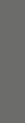

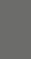 \\ (1)

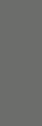

a

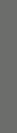 \\ $=$

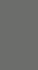

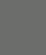

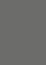

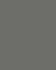

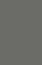

.

.

.

(

(

(

(

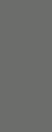

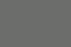


The arts cover the areas of fine art, performing arts and music. In my research I have tended to focus on the market for fine art, yet the work can be extended and broadened more generally to other arts markets.

In the primary market the main players are galleries and dealers, who provide a showroom for emerging artists to sell their work for the first time to collectors. Dealers establish prices for the art and to maintain client integrity information on the transactions are withheld and data is sparse. Olav Velthuis is one of the few researchers who, has worked considerably on galleries and dealer markets (Rengers and Velthuis, 2002).

In the secondary resale market, trading takes place. At auction art experts provide estimates prior to the auction, providing an estimate of the intrinsic value of the artwork. Typically a lower and a higher estimate are given, with the range reflective of the uncertainty in the expected market price.

Art price data from art auctions provide an extremely interesting case for examining valuation. Long run returns to art markets capture how much we as a society price the arts over time. The real rate of return ${ }^{\mathrm{I} 3}$ of fine art has appreciated over time. As with most markets there are cycles of price rises and price falls, reflecting changing tastes for particular genres of art, the economy, and other influences (Gerald Reitlinger, I96I).

During periods of extended price appreciation, there is typically renewed interest in the financial (investment) value of art. ${ }^{\mathrm{I}}$ Here the focus is on the resale value, and investment is made on the basis of a higher expected resale value. This is certainly not a new phenomenon, and is considered in the literature during the I920s, I960s, I980s, and again during the recent resurgence since the millennium.

Arts markets have been flourishing globally with rising prices. Auction data has become more prolific. The auction market has therefore become indisputably more transparent. These changes reflect a changing art world, with issues

I3 Is the rate over and above the pace of inflation captured by the consumer price index.

I4 See Richard Rush (I96I), Frey and Pommerehne (I989), Mei and Moses (2002) and Campbell (2008a) and Kortewijk (20I5) for examples of the art investment literature over the decades. 
such as values, trust, liquidity, all playing an inherently important role in characterising the arts, culture and society.

We have seen how valuation is inherently subjective. Art is bought for its subjective value and provides us with the possibility of being able to price some of the subjective values and non-pecuniary benefits that are often externalised for financial goods. From my perspective, the subjective nature of art valuation makes it an interesting and intriguing area for research and from which we can learn an enormous amount of information on the heterogeneity of behaviour and preferences. With coauthor Leonard Wolk, using data on individual bidders we observed that the tendency to overbid when one is new at auction reduces over subsequent auctions, and it takes experiencing at least five auctions to learn not to overpay at auction (Pownall and Wolk (2013).

Understanding preferences is one of the mainstays behind the movement in behavioural finance. Typically preferences are revealed through individuals' willingness to pay (Paul Samuelson). However preferences fall fallacy to change (Joan Robinson) and are heterogeneous ${ }^{15}$. In contrast to revealed pricing, characteristics or hedonic model $\mathrm{s}^{16}$ enable us to look at the weight given to various characteristics, (Griffith and Nesheim, 2013).

These models have provided empirical researchers in art markets with a tool to address the issue of subjectivity and bring some objectivity to this field by observing how particular traits, characteristics, and thus taste is valued by society at large.

There are certain attributes and characteristics of artworks that can be priced. For example the most important constituent of an artwork's price is who painted the artwork. The artist is by far the most significant and important variable when pricing art. Other significant factors are size, genre, medium, and the auction house involved in the sale. Above all these particular characteristics, there is a non-observable uniqueness to particular artworks, which may receive a value far beyond what characteristics pricing can put a hedonic value on.

\footnotetext{
I5 See the seminal work by Paul Samuelson and Joan Robinson.

i6 Traditional characteristics models they are also referred to in the literature as hedonic models or shadow pricing models.
} 
This is a latent variable, which is difficult to capture using the characteristics pricing approach. Characteristics that evoke strong emotions, such as poignancy, catharsis, or are disarming, or confrontational, or that may induce sentiments of sadness or fear, yet are latent in a quantitative model of prices.

In an attempt to capture emotions, mood has been proxied in the finance literature using the weather. With coauthors Dakshina de Silva and Leonard Wolk, we extended this literature for the art market, and used data on weather in London (where it is notorious for a high rainfall) and found that on particularly sunny days in the winter period, there was a significant positive impact on prices. This was particularly strong for lower priced paintings (See De Silva et al. 20I2).

More recently I have been interested in quantitatively measuring the subjective value of colour. In a paper focusing on the colourful artworks of Andy Warhol I find evidence of a premium for his darker works, Pownall (20I3). I am particularly interested in developing this research as it helps in our understanding of how individuals value such subjectivity. With coauthors Charles Noussair and Luc Reneboog we have recently been investigating this further.

These methods also fit particularly well with how valuation can be tailored to individuals, depending on the intensity with which these various characteristics are weighed. This can be extended from artworks to all types of cultural goods in more generality. For example collectors of the arts obtain a large aesthetic benefit from holding art, (or emotional dividend), from owning and collecting beautiful objects (De Roon et al. (2008)). It is no coincidence that art is often termed a priceless object, thus the positive subjective value is far greater than any objective hedonic measure could price.

The method of characteristics or hedonic pricing enables researchers in art markets to establish how these coefficients change over time. The changing weight attributed to painting characteristics is reflective of how the value placed on average various painting characteristics' change over time. If one focuses on the variation placed on the time at which the artwork was sold, then one can use these values to construct a price index. 
There have been continued efforts to provide art market indices to reflect the periods of rapid appreciation in art prices. When the market frenzy dies down, and the market dries up (less-liquid), with few art sales taking place, interest wanes, and only with a resurgence in art sales prices, and record breaking prices hitting the headlines is interest measuring the return to art from the appreciation of art price indexes, reignited once more.

For example, in the early I96os the art investor Richard Rush provided graphs of art price movements for a variety of art market genres since the I920s. In I967, Geraldine Keen, working for The Times newspaper, together with Peter Wilson, the Chairman of the board of Sotheby and Company created The Times Sotheby Index of Fine Art Prices, with the aim of producing a monthly index in the Times newspaper using art auction sales from Sotheby's Auction House.

These efforts to measure the extent to which art prices had changed over the years, on average in various different fields of the art market have benefitted from the methodological improvements from similar types of indices established for observing house price movements in the real estate finance literature. See Beulens and Ginsburg (I993), and Goetzman (I993), for early applications of both the hedonic characteristics pricing and developing upon the work of Bailey et al. (1963) and Case and Shiller (1987) to construct repeat sales methods using data collections on art sales prices from Gerald Reitlinger (I96I) and Enrique Mayer (I97I-I987). This approach was later extended using a more comprehensive collection of auction sales data for New York by Mei and Moses (2002).

One advantage of using repeat sales to create a price index is that the researcher need only look at changes in prices over time. One does not need to model using characteristics any particular non-observable characteristics. The assumption is that these non-observables stay the same over time. Thus having the advantage of not requiring all the artworks characteristics to be defined. Provided one has sufficient data on the prices at which identical paintings sell for, the method will result in a good approximation of the influence of time on price. 


\section{Pownall's Fine Art Indices}

\section{- London - Amsterdam}

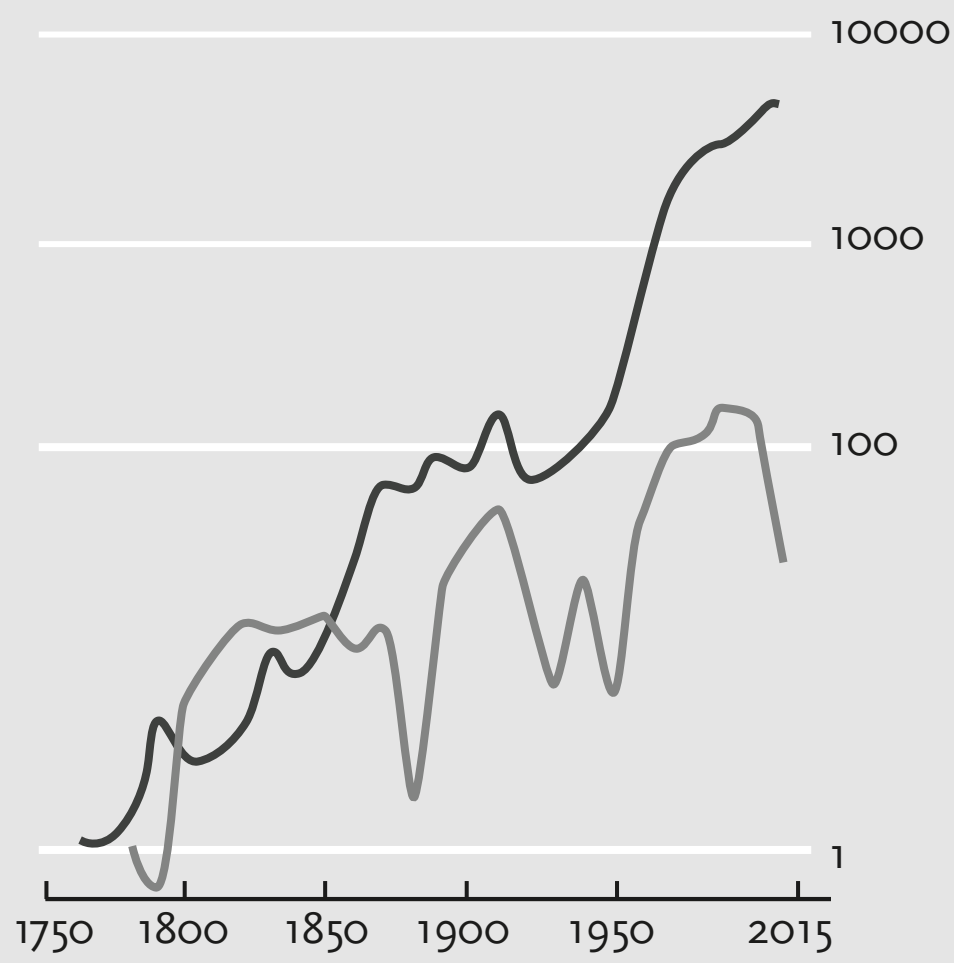


I was particularly interested in the behaviour of the London and European arts markets. It was a challenge to collect a large complimentary database to the Mei-Moses repeat sales index, so that I could estimate long run indices to see how the London and European Art Markets are priced. The efforts were rewarding, as I have been able to construct indices with over 20,000 repeat sales of historic repeat sales, from both Sotheby's and Christie's auction houses, with initial sales dating back to 1776 when Mr. James Christie himself was the auctioneer. The creation of fine art indices using this data is a unique collection of data for the London market. This data constitutes to the Pownall's London and European Fine Art Indexes, and are also a constituent of the Mei Moses Series of All Art Indexes, used as a leading benchmark worldwide ${ }^{\text {I7 }}$.

Taking a long run orientation we can learn from art market history. This is helping economists to gain a more influencing role in the creative economy with policy makers, see Towse (20II).

The data runs through to the end of 20I4. In the first figure we see the cyclical nature of the art market. There are periods of extraordinary growth, followed by periods in which the market index falls. Liquidity is inherently low during those periods, such as the First and Second World Wars. Currently the London market accounts for around a quarter of global sales, estimated in the TEFAF Art Market Report at having reached over $€_{50}$ billion of sales ${ }^{18}$.

During periods of high inflation, art has (perhaps inadvertently) been used as a vehicle to hedge against eroding prices. If considering the price appreciation of art over time then one must take account of inflation, and from a practical stance, extensive transaction costs. Initially we looked at the performance of the London and Amsterdam art markets in Campbell (2008a) and Graddy et al. (2008) using methods to adjust for hetroskedasticity.

I7 For example in the Financial Times, The Economist, Deloitte Art and Finance Report (20I5) and recently in the Citi Global Perspectives \& Solutions (20I5). The other predominant provider is Artnet, whose data is complementary to ours.

I8 Art Market Report, by Clare McAndrew (2015). 


\section{Pownall's London Fine Art Index Postwar Inflation Adjusted}

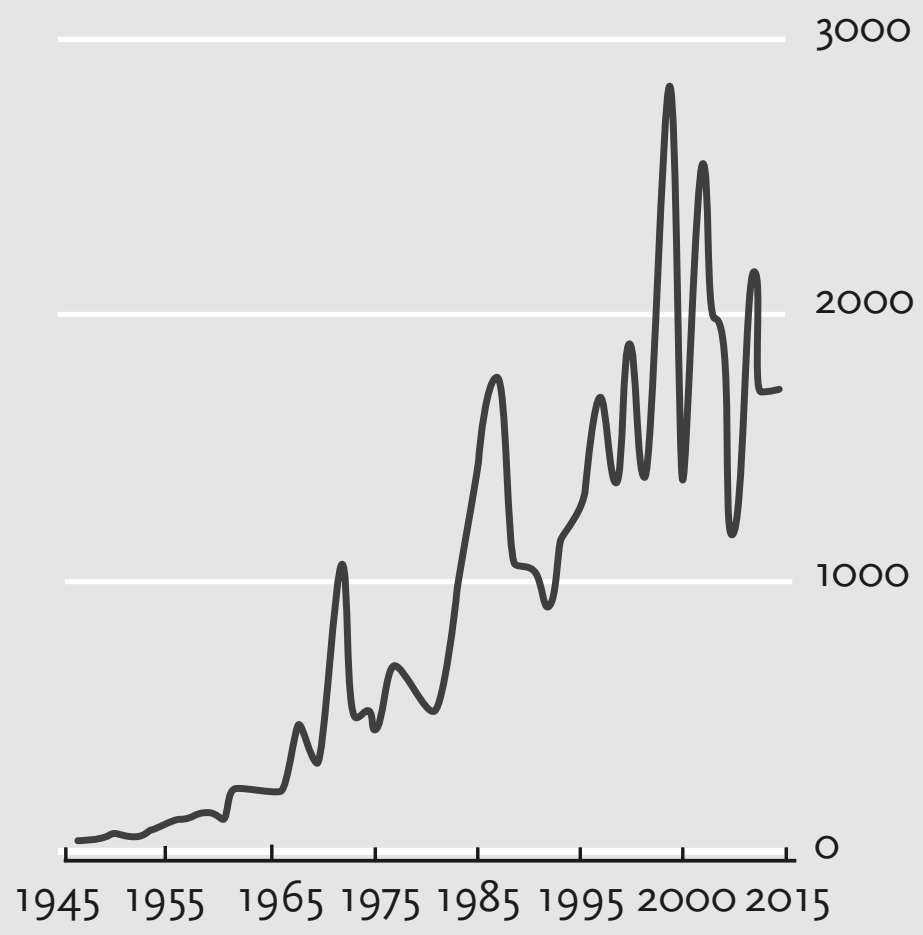


In the second figure, I have rebased the London index back to I for postwar sales. This enables us to focus on this more recent period more carefully. Analysing the returns to art one finds an unprecedented growth in the market over this period. The annual growth rate from I776 until the end of 2014 is $5.315 \%$. Adjusting for inflation we find that the real annual growth rate is $3.156 \%$. This is comparable to the rates observed by Baumol (1986), Beulens and Ginsburgh (1993), and Goetzman (I993), Mei \& Moses (2002), and more recently in Goetzman et al. (2OII) ${ }^{20}$.

For Amsterdam sales we find an annual growth rate over the period I779-20I4 of $3.676 \%$, slightly lower than for London. Although higher growth was observed in the early part of the index until I 820 , the rate flattened off and fell in real terms. By the beginning of the $19^{\text {th }}$ Century the growth was again exuberant. Also the art market flourished in the Netherlands post WWII, and has only decreased in the very recent period, with sales moving to the major art centers such as New York, London, and Hong Kong, China.

Whereas the London market exhibited large growth at the turn of the I8th Century, and a prolonged period of growth from the I85os until the beginning of the Twentieth Century. Post Second World War there has been cycles of growth and decline during the I960s, the late I970s following the oil crisis, the late I980s, with an almost unprecedented bubble occurring in I990-I99I, with the Japanese interest in the art market, particularly in Impressionist paintings. Recently following the 2008 financial crises we can observe a very volatile market with excessive swings occurring.

During the periods of art price falls, there are much fewer transactions occurring. The market tends to dry up (illiquid market). The auction house sales reflect the most attractive part of the market and although the bias induced by focusing on leading auction houses can be criticised, it does provide a good indication of price movements over a long period in time.

I9 Geometric mean rates of return are given. Using arithmetic means generates a slightly lower real return of $3.12 \%$ for London.

20 The studies in the literature do not take account of transaction costs. 
Fine Violin Index

15

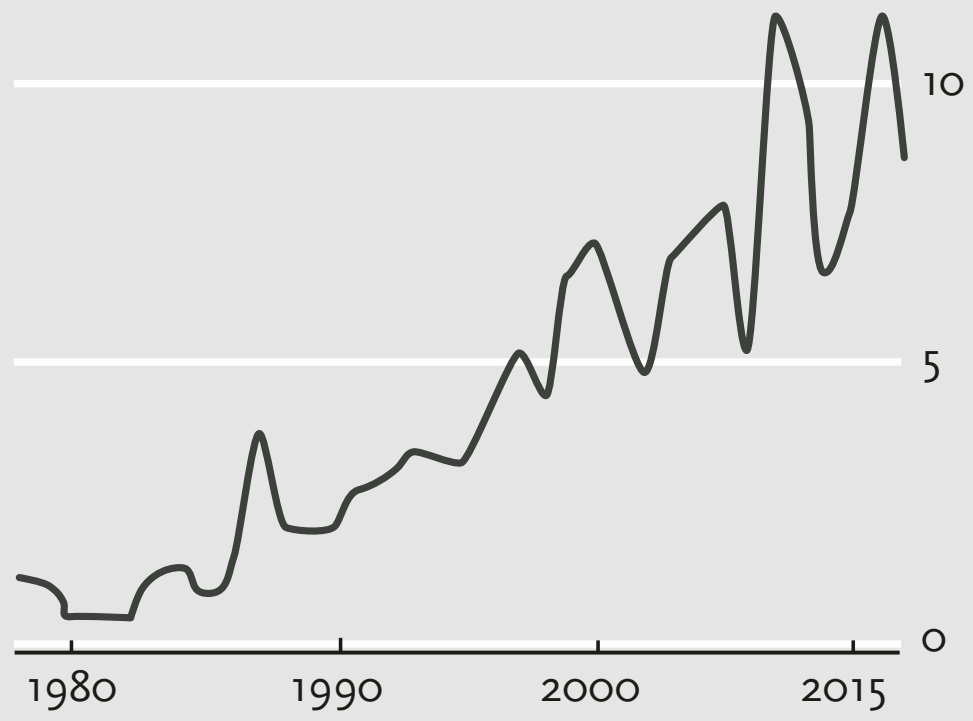


The methodology can also be adopted for other arts markets, and for representation I also include an index that I have created for the Fine Violin Index2I. The dealership and restoration workshop associated provides a source of funding and support to young Violinists.

Quantitative models are mere aids and provide us with tools to help in our understanding of the prices and values of arts markets. As academics we must remember that we can never do justice to adequately modeling the beauty of art, and the arts in society. I find it fascinating that pricing the latent unobservable factor is the aspect we still have the most to learn from. This compelling notion will no doubt continue to drive us as a society forward.

2I I thank Florian Leonard personally from Florian Leonard Fine Violins, a Restoration and Dealership of Fine Violins, for very kindly providing me with information on his fine violin collection. 
The arts and finance 43 


\section{Art finance}

'The value of a Caneletto will never go to zero, it will never do an Enron or a Marconni.'

- Philip Hoffman

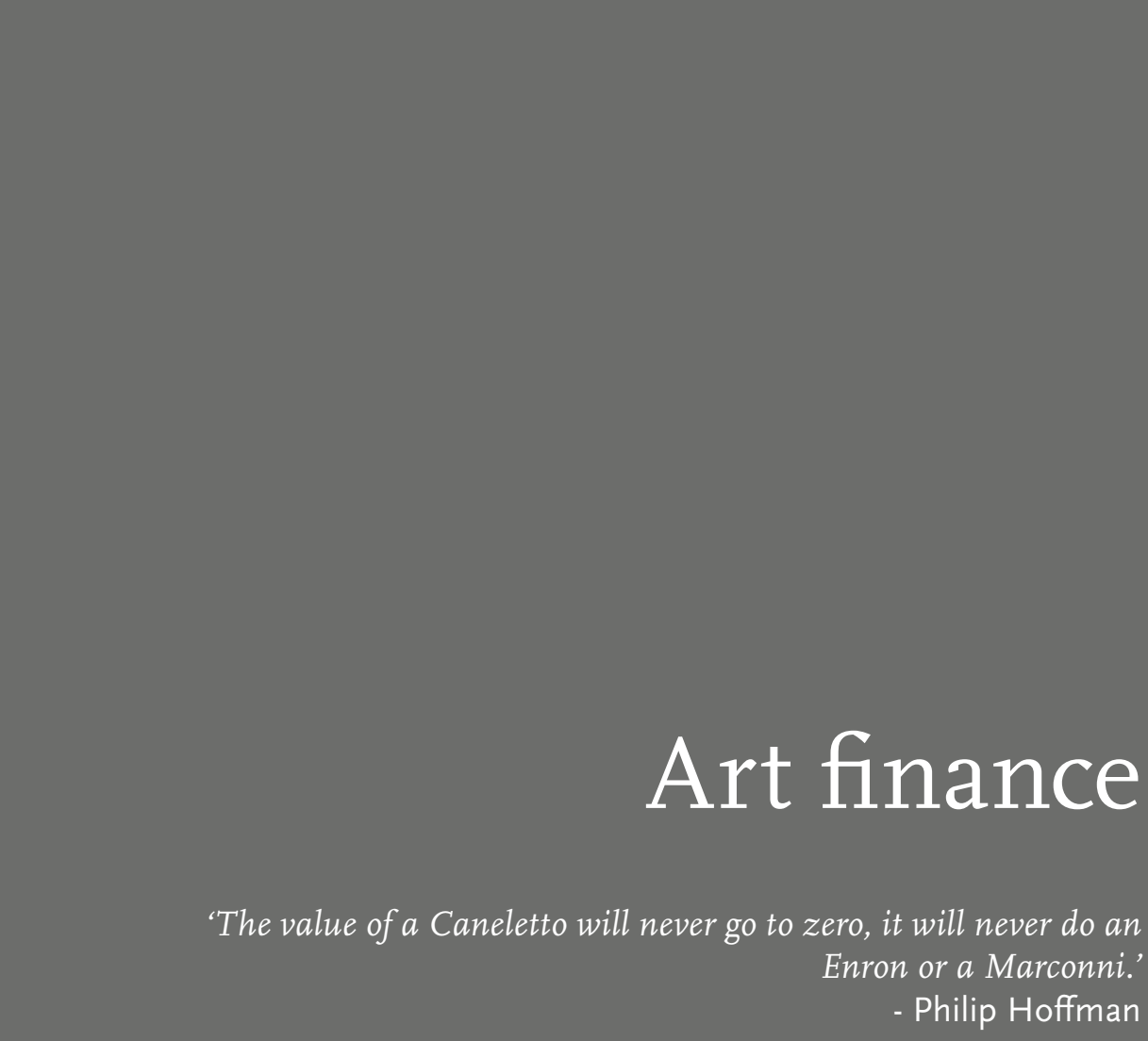


Family officers and wealth management firms have long been aware of the importance of providing art advisory services to their clients to preserve the valuation of their clients art collections. Direct investment in art is certainly not new, but awareness of price movements and risks are changing the art finance landscape.

A flourishing art market at a time when other asset classes have showed relatively poor performance has raised debate and discussion again over art as a financial investment. Boutique art investment funds focusing on the investment value of art enable investors to indirectly benefit from the appreciation of art prices.

Although there are more possibilities open to investors toady, the concept of indirect investment can be dated back to at least the beginning of the twentieth century. Syndicates and clubs of collectors have traditionally formed a vehicle to finance art. Interested in both the resale value as well as the aesthetic value of the artworks. Often cited is the Parisian based Peau de L'Ours club, in I904. The British Rail Pension Fund, during the epoch of high inflation during the I970s is one of the largest known institutional investors to use the arts markets as a means of storing value. They predominately invested in fine art and sculptures. The return to which outstripped the pace of inflation at the time and was deemed a success.

Whether art can be considered a separate asset class had been highly debated. Currently there is much debate on the developments in art-finance, and the diversity of structured products available for indirect investment into the art market. Although art does not strictly generate a cash flow, the rental value of art allows one to consider art as an asset class. The launch of many art investment funds has paved the way for this new asset class22.

New platforms for trading art online and also the availability of online data has sparked renewed interest in tracking price movements and in a tradable art market index.

22 In 2004 I spoke at Fine Art Fund conference at Sotheby's Auction House in London on Art as an Asset Class'. 
Structured solutions for managing risks associated with the art market are becoming more prevalent. Frank Fabozzi included a chapter on art finance, which highlights developments in this field in 200823 . Art structured products to manage risk have developed; insurance products, guarantees (Graddy and Hamilton, 2013), art derivatives, and art credit default swaps for loans against artworks (Pownall and Weihenkamp, 2008). These estimates are also used strategically by auction houses in attracting bidders, particularly at the higher end of the price distribution, for more expensive highly valued paintings. They are also typically smaller when the auction house offers a guarantee see Graddy and Hamilton (20I5).

These developments in the art finance field are all in part related to understanding the risks and returns to art, and how prices relate to values.

Although the subjective value of a 'Caneletto' may to some collectors never fall to zero there are other reasons why the price may indeed go to zero. Changing tastes change demand for particular genres and prices reflect this. Thus one would expect artworks with a richer art history to show less variability in price (the idiosyncratic risk is less)24. Those with less of a track record will tend to show more price variability since there is uncertainty surrounding their future value. Thus Contemporary art by its very definition will be more risky.

Prices may even fall sharply if a particular genre goes out of favour, thus exhibiting high downside risk. This would also occur in the event that the artwork is thought proven to be a fake or a forgery, thus reputable provenance is key. Provenance is indirectly captured by the genre and the year of the painting in characteristics models of art pricing.

Arts markets therefore provide us with an interesting case to observe how volatility is actually capturing the uncertainty surrounding market participants' forecasts. Valuation of venture capital for start-ups is akin to the issues

23 See Campbell (2008a).

24 During the Fine Art Fund Sotheby's Conference in 2004, I suggested that Old Masters are the 'Blue Chips' of the art investment world. I prefer the analogy to value stocks. At the time, I also likened the Contemporary art market to technology stocks. Today I would liken valuing Contemporary art to valuing venture capital. The difficulties associated with valuing a start-up with (often) no cash flow are akin to the difficulties from valuing art not yet having secured a place in art history. 
of valuing contemporary art. There is uncertainty on how the Art Historians of the next generation will value the Contemporary artists of today. Thus there is subjectivity and greater risk, than in the case where markets have greater knowledge. The uncertainty that a particular artist (or genre) goes out of fashion certainly exists, but from a cultural heritage value this is less likely to be the case for the most reputable and established artists. The issue of reputation, and trust are imperative in this setting.

A current avenue for research in this area is analysing the individual return distributions of individual artists. Using the London art data I present this risk-return relation here today for you, part of ongoing work in this area to help us further our understanding of subjective values and objective prices.

By focusing on the price appreciation of identical fine artworks over time, we see for example from the I2 most liquid artists in the auction resale market over the long run with a minimum of 40 artworks that sell more than at least once, and for many artworks there are multiple sales. Interestingly the trade-off for individual artists is a relatively straight line. The art market over the long run appears to be rather efficient in terms of rewarding investors with higher rates of price appreciation for artists that are more risky, in terms of the variability of individual artworks' resale prices.

At the level of the individual artists, without the possibility to take into account any diversification benefits from the disharmony in the movements of artists or movements over time, I find a strikingly positive trade-off between risk and return. It would appear that there is sufficient idiosyncratic risk within artists' repeat-sales distributions that is helping to contribute to a diversified collection from a market price risk perspective even by holding a single artist.

Although individual idiosyncratic risk still pertains, it can be seen that work for example by Joshua Reynolds, Raoul Dufy and Pierre Auguste Renoir generated high returns to art, albeit with a greater dispersion in the prices over time. Similarly those artists, whose artworks prices with less variability in the market also exhibited lower returns over the same period; such as Marc Chagall and David Roberts. 
What does this teach us about art collection management? For Old Master collectors, where diversification is unlikely to take a precedent, the focus is simply on buying great art. We can take comfort in the finding that the resulting strategy is fairly efficient at least in the long term.

Observing individual return distributions across artists provides an objective measure of how price appreciation relates to risk. Given sufficient data, any discrepancy in the empirical return distributions across artists is subjective and provides a measure of a latent unobservable factor. Stylised aspects such as reputation and liquidity here are additional factors that contribute to overall risk in the measurement of risk. In pricing it is these latent variables that we still have the most to learn from. From a practitioners perspective it is crucial to mitigate the risks that accrue for artworks that do not have a strong provenance. It makes sense to buy the best you can afford, from a reputable dealer, auction house, or art fair, where these additional types of risks are reduced.

The variability of prices is greater for Contemporary artists (not shown here), but so also is the expected reward in terms of price appreciation. Of course this type of analysis provides opportunities to look across a greater range of artists, akin to stock picking. Those with the highest expected risk adjusted returns will be more appealing from an investment perspective. Predicting the taste of the future is key, and you may be skilled or lucky. But if you are concerned about the future resale value of your contemporary art collection, or as a Contemporary dealer or museum, it is essential to diversify across a number of less established Contemporary artists to reduce those financial risks.

Supporting a number of young less well-known artists, many of whom scrape to make a living, provides a lottery styled strategy where the upward potential can be huge, whilst limiting the overall risk of the collection. For established artists, it is less important to hold a diversified collection across artists. Which is also good news for museums and art collectors with well-renowned collections. 


\section{Artists}

\section{Source: Pownall's London Fine Art Index}

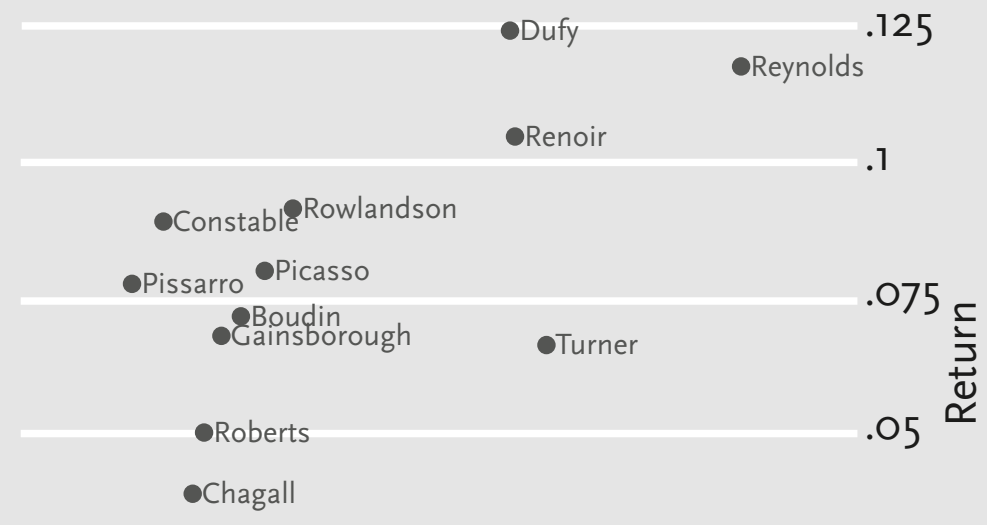

.025

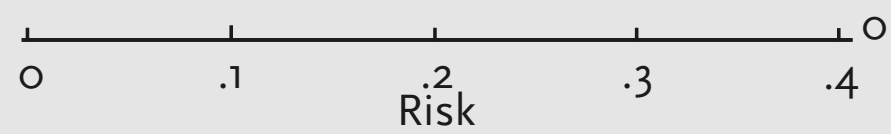


Art markets price in subjective values. Do financial markets?

Standard models in finance relate risk to volatility. As the market moves up, as in a 'bull market', markets become less volatile. However it is during such times that the deviation from the normal (or average) is higher. There is greater fear of potential losses. The concept of reversion to the mean establishes this empirical finding. Yet it is the concept of greater induced fear that appears to be driving this greater aversion to potential losses. The overall subjective downside risk is greater and the probability of extreme downside returns weighted more heavily. For art markets this weighting on the downside is likely to be less. Whereas financial markets become inherently more uncertain during such periods, art markets become less uncertain.

Similarly, value stocks have less uncertainty, thus the subjective risk is less. As with Old Masters, and paintings with more fundamental value, the rate of return is lower, as the overall uncertainty is less. Likewise, growth stocks have greater potential downside risk, as prices may be inflated due to differences in subjective expectations.

In the wake of the global financial crisis and the low level of trust in financial markets typically creates high subjective uncertainty, a precursor in explaining high returns to investment. Psychology is inherent in all markets, yet we observe this behaviour in art market directly and this can help us understand the behaviour of broad financial markets. It can help us understand the reasons behind the various factors in asset pricing.

Related to all the developments in the art finance field to measure and interpret risk, institutions and organisations are trying to provide products and services that reduce the risk from their core business.

In the next section I profile the Van Gogh Museum, with whom I have been very fortunate with my position at TIAS School for Business and Society to have been able to partner with to aid the development of education and learning in this area, which is also of important relevance for this new position here in Maastricht and within MACCH. 
The arts and finance $5^{\mathrm{I}}$ 


\section{Museum management}

'Do not quench your inspiration and your imagination;

do not become the slave of your model.'

- Vincent van Gogh 
The period surrounding my appointment as a professor of art and finance at TIAS School for Business and Society, in conjunction with my work and position with the Van Gogh Museum, has given me the opportunity for me to reflect upon the issues surrounding financing the arts. Public policy, not only in the Netherlands, but globally has resulted in changing attitudes towards how museums and other types of creative enterprises are managed and funded.

The discipline of the economics of the arts, also referred to as cultural economics, analyses the economics of the creative industries, from film, music, performing and visual arts. How collections are managed and how a museum manages its collection is becoming increasingly important as the number of museums is growing at a staggering pace globally, and fundamentally, because museums are becoming more accountable to their financiers.

From a financial perspective art financiers have historically been wealthy families, traders and merchants. The pendulum of art finance has swung between the private and public sectors over the decades. How the arts are financed has always been a challenge and a debate. Recently, the predominant force has again seen a strong movement to increasingly encourage funding back to the private sector. Lottery funding has become a popular funding mechanism within Europe, however private funding is becoming increasingly important.

Museums are inherently focused on managing their revenue streams, and also their exposure to risk. The Van Gogh Museum is an excellent case of a museum that is at the forefront of managing this exposure. Reliant on tourism, and a limited number of works of art from the Van Gogh collection, it is imperative that they consider diversifying their revenue stream. $80 \%$ of the revenues are based on museum visitors, so a potential loss in income from dropping visitors, such as happened from the volcanic eruption of Eyjafjallajökull, reduced visitors travel to Amsterdam, in 20 Io highlighted their sensitivity and susceptibility to global risks. With natural disasters and terrorism a growing phenomenon it is incumbent of the Museum to act to manage these potential risks. 
Finding other revenue sources is an imperative part of the Museum's strategy through diversification of the reliance to income stream they can reduce the risks. Whilst maintaining the strategic objectives of the museum to be provide a stimulating and enriching experience, which is innovative, and widely accessible. Obtaining funding to finance alternative projects to realise these alternative revue streams is not an easy process. With a high reputation it is important that associations are made with the correct partners. Even issues that public funding is not spent on too 'risky' endevours.

In times of austerity, government funding is reduced and initiatives towards private sector funding are encouraged. Typically for art institutions they are hit most hard in times when they most need subsidizing. As this is the time when the general public spends less during visits to arts institutions. Interestingly they probably benefit the most from the arts in times of austerity. The marginal utility from visiting a cultural event could be argued to be greater during periods of economic downturn.

Inspiration and creativity gained during hard times is renowned to be great. Often the most inspiring periods in fine art, music and in performing arts one could argue to have occurred during the period at which the economy is at its lowest. Reconciling the apex of innovation and creativity with the trough of the economic cycle is a challenging and interesting aspect worthy of pursuit. Evidence that the effect of the arts on the economy is at its greatest during times at which the economy is at its worst, would provide a formidable case for improved funding to the arts during periods of classical austerity.

However, with a greater understanding of the mechanisms with which the returns from the arts are benefiting the wider community Governments are again realising the potential that spending through the arts is having on the overall economy. As the richer economies move towards greater service provision, and with consumers demanding arts entertainment in the form of a much larger proportion of the public (than ever before) attending museums, exhibitions, and art fairs, it is becoming increasingly important to recognise the influence of arts spending on gross national product.

The notion that the marginal utility from spending on the arts is dependent on the state of the economy is an interesting area for further research. The margi- 
nal disutility of tax is also dependent on the state of the economy and potentially also at its' highest also during periods of austerity. The rate at which utility is increasing or diminishing is of key importance.

The sensitivity of the individual towards the increasing or diminishing rate of marginal utility again relates to the value function in behavioural finance. For those who enjoy the arts, the affective response is larger and hence the willingness to pay is affected accordingly. The arts highlight the relative state dependence of marginal utility and to how we measure risk in standard finance. It is this aspect that interests and concerns me.

Research in this area, so that we harness the power of the financial markets to provide lending to such worthy causes, requires a true understanding of the costs and benefits to society. I believe it is this mechanism, by valuing non-financial risks and returns that will incentivise lenders and financiers to provide capital to financing areas that currently receive less funding due to the low relative risk adjusted returns. The returns are higher when incorporating the positive externalities such as the enrichening experience to society. Taking into account the subjective risk, the overall risks are lower from investment to the arts. ${ }^{25}$

As an academic institution, partnering with arts institutions such as the Van Gogh Museum, the Royal Academy, Sotheby's Institute of Art, and TEFAF provide a platform with which to help educate not just arts experts about finance, but also finance professionals about the arts. This should begin within the undergraduate level and not just at the post-graduate and executive level. Culture should also be a part of the ethics and sustainability efforts that are part of University's education programmes. Changing the culture of finance requires greater exposure to the arts and culture.

25 This relates directly to the risk-as-feelings hypothesis from Rottenstreich and Hsee (200I) that I ascribed to earlier. 


\section{Creative}

\section{industry finance}

'Art is the effort to create beside the real world, a more humane world.'

- Andre Maurois 
Recently I have been able to provide a broader perspective on the research and implications of my research to date within the wider landscape of other creative industries.

In conjunction with my work at Maastricht University and also at MACCH we have been involved in providing policy advise to the local municipality. This has given me the opportunity to reflect upon the wider issues surrounding financing the arts and creative entrepreneurship.

As outlined earlier here, research into the arts indicates the positive externalities to society and the economy from investment into the creative industries. Enriching lives, through social wellbeing, and through higher productivity from inspired, engaged, creative and innovate individuals, will boost our economy overall. Economists tend to think in terms of 'no free lunch', well, in addition, as Economists we need to fully incorporate into the price of that lunch the value from that lunch. How that lunch hour, for example, contributed to overall productivity, spent perhaps together with colleagues, sharing ideas. Considering the reduction in potential costs, i.e. spent on achieving similar objectives in team building exercises with external consultants, and from an increase in wellbeing. These all have non-pecuniary value that could be measured in terms of reducing future risks - on the company budget and in healthcare.

Public policy, not only in the Netherlands, but globally has resulted in changing attitudes towards how creative enterprises and other types of creative enterprises are managed and funded: microfinance; crowdfunding; platforms which allow for greater community sharing in the profits. Developing these initiatives further whilst advocating the value of the arts and culture is a crucial first step in helping direct funding to these areas.

Governments worldwide are tapping into the creative industries as one of the fastest growing areas of the economy. The demand for the arts and culture as forms of entertainment during increasingly fragmented leisure time is valued at a premium. Yet it is still vastly underfunded and the knock-on effects are not incorporated to the full.

I look forward to having the opportunity to help make a change. Maastricht has been extremely good to me, and I hope that I can give back to the city and also be good for Maastricht. 
Cultures of art and finance

'He who rejects change is the architect of decay'

- Harold Wilson 
Finally, I would like to use this opportunity to address the differing cultures of these two disciplines. Moreover, I would like to reflect upon what can the arts learn from finance? And what can finance learn from the arts?

My intention of this inaugural address is to enlighten us in finance to the broader metrics beyond analysing financial risk and financial returns, when interpreting the relation between risk and reward in decision-making under risk.

The customs and beliefs in behavioural finance have led the field in establishing that cognition and perceptions are important in understanding in reality how individuals make financial decisions. Taking this a step further to understand how our sentiment, issues of trust, and how evocative emotions are, all take center stage in influencing the uncertainty surrounding decisions helps to reconcile classical finance theory with how financial decisions are made in reality. Taking this even further such that a more integrated holistic approach to financial decision-making would incentivise us as a society to focus on the aspects of our society and culture that have crucially cost us in order to reap economic growth, would help us tackle many of the societal issues that currently face us.

The current practice of outsourcing the inputs of production to the most profitable source is a false economy. The short-term gain comes at the longer-term cost to society. To make financial decisions that also take into considerations the costs to society and the environment, without relying on the mechanism of the government to redistribute it is vital to educate individuals about the value-chain associated with the production of those goods and services. The culture of finance needs to change to reflect the values beyond the sole metric of profits. Rather than squeeze the system so tightly for every ounce of financial gain, thought and consideration of how companies make their returns to investments, will put greater value on the externalities that have been created in this process.

We have all witnessed and experienced the effects global financial crisis, which has been the largest and longest period of recession (depression) in history. This crisis is a legacy of the process of externalising social and cultural values when making financial decisions. Greed from most actors in the system, from bankers, brokers, public employees and also consumers, 
incentivised by a system of focusing on individual rent seeking, at the cost of society, exacerbated the crisis.

The greater risk borne by society at large needs to be taken into account when making economic decisions. Magnified by the uncertainty in how our changing climate and ecosystem is affecting agricultural production, energy reserves, with record droughts and catastrophic weather events on the increase. The risks are likely to only increase in the future. After the global financial crisis there was much debate about the drastic need for cultural change. However, the discipline has reverted back to the same mechanism of traditional financial decision-making. Financial decisions should be made with a conscience. The fiduciary duty of institutional investors and corporations should be to make more conscience and strategic decisions, rather than rational decisions. The importance of such societal issues as community and trust can be effectively transmitted through the arts.

The arts provide us with a creative means to provide awareness, to educate and to learn to value many of the 'externalities' that have been created in our disconnected economic system. It is important to empower people and businesses through incentives so that we value our natural environment, our society, and our cultural capital. We need to take a much more integrated, enlightened and holistic approach to financial decision making.

The culture of finance can learn from the culture of the arts to make more conscience and accountable financial decisions. Extending our value base in finance will also be beneficial to funding the arts. If financiers value more than just financial reward, then the social and cultural values will receive more attention. Their impact on society will be more highly valued, in line with their true impact and thus value on society. Social and natural capital, currently underpriced in the economic system, needs to receive the attention and value, reflective of the cost of the resources. Money will flow to these resources if they are priced within our system. Currently it does not.

I end this talk with two focused research challenges. First there is currently much interest in being able to value the social and cultural impact, alongside economic impact. For example urban parks provide more tangible qualities such as the value to society from converting carbon dioxide, storm control, 
dampening noise and pollution in cities. Because these have direct knock-on effects for public health, then estimates to how much can be saved in the provision of healthcare helps to justify the preservation of city parks and green spaces. That is without even considering the value to real estate from residing in the vicinity of an urban park. Such methods can be translated to the arts and the wellbeing of individuals. Providing the correct incentives to lenders and investors in the arts to facilitate this process requires educating investors and consumers about the value-chain.

A point of contention as an example; is it fair and just that house improvements and repairs on bicycles are charged at $6 \%$ value-added-tax in The Netherlands, yet restoration of artworks are charged the full 21\% VAT, as if they were new consumption goods? Amending this would be an important policy move to support the arts.

Secondly, beyond providing incentives through subsidies, incentivising returns in the form of sustainable, quality and long-term payoffs require key performance indicators related to the returns of other characteristics other than financial returns. Incentives that encourages a long-term strategy will foster more trust and collective behaviour. Society requires less individualists and more teams, establishing long term tractable metrics is an imperative part of this process. 


\section{Conclusion}

'The difference between what we are doing and what we are capable of doing would solve most of the world's problems'.

- Mahatma Gandhi 
John Stewart Mill defended the right to freedom of speech, this I have always highly valued. I am highly privileged to have been able to speak here today to present my inaugural address. I hope it presents a convincing case for replacing the classical narrative in finance and economics, which is ideologically driven, with a narrative of enrichment, which allows us to maintain rationality and market efficiency, but by adding depth to the discipline. By exploring what happens when a scientific and arts narrative are interwoven I have been able to reflect upon a number of gaps.

Reflecting upon a number of gaps, I initiated this talk with the concept of a gap between the costs and benefits to society due to the presence of externalities, thereafter I discussed the gap between theory and practice due to the presence of considering uncertainties and not just risks. This reflects the gap between classical and behavioural finance. I continued to discuss the gap between values and prices that equates to the gap between subjectivity and objectivity in empirical pricing. As academic researchers in the social sciences we are interested in measuring these gaps and closing these gaps.

Affective psychology can help us explain these gaps. How we as a society value pleasures and avoid pains captures the value from the non-pecuniary aspects of goods and services. For example, greater mistrust, low morale, lack of information and knowledge all result in greater uncertainty. As does environmental damage, the cost of health and wellbeing of the labour force. Thus the externalities arising from focusing on shareholder profits comes at the greater risk to us all. This was reflected in the global financial crisis, where risk and uncertainty were underestimated. By focusing on the positive externalities, we can therefore also reduce future risk and uncertainty. For example higher standards of education and skills, more creativity and outlets for expression all pertain to less future uncertainty. As does, a healthier workforce and higher societal wellbeing. In decision making under risk, it is by taking account of these subjective risks, and reinterpreting the relation between risk and return, thus will help the flow of funds to investment in so-called green financing, social impact bonds, and cultural organisations and initiatives.

Capturing the affective values, which have an enriching affect on us, we learn to price both the additional returns to society as reductions in risk. The discipline of finance needs to learn from the arts, and thus the arts will benefit from more finance. 


\section{Words of thanks}

'Let us be grateful to the people who make us happy; they are the charming gardeners who make our souls blossom.'

- Marcel Proust 
At the end of this inaugural address, I must thank you all for your attention. Please, allow me to take a few moments of your time, to thank those who have supported me over the years. Like many people here today, I owe a huge debt to some visionary scholars, many present here today. I am enormously grateful for your inspiration and confidence in me. As well as those here today who have made my appointment as professor of art and finance at this university possible.

Distinguished Boards, President and Deans of Maastricht University.

Distinguished colleagues here at Maastricht University, TIAS, Tisem, the at Erasmus University Rotterdam.

I would like to extend this thanks to the Maastricht Centre of Arts and Culture, Conservation and Heritage for their the initiatives in bringing together the close cooperation across three faculties here at UM - the Faculty of Arts and Social Sciences, School of Business and Economics, and the Faculty of Law for allowing me to join them in sharing in the ambition to educate and contribute to policy in the arts and finance, and also for organising this annual conference, which this ceremony today also forms an integral part in establishing our ties and commitment. Thank you in particular to Dr. Vivian van Saaze and all the other members of the Steering Committee. I look forward to strengthening our working ties across the various initiatives that are taking place here and how we are reaching out to many of the art institutions such as with Professor Laurenson, Pip here, at the Tate, with the TEFAF which is currently on in Maastricht, Furthermore to Sotheby's Institute of Art, for inviting me over the years to teach on your Art Business program. And to the Royal Academy of Arts in the UK for initiating our more recent collaboration, I very much look forward to these developments.

I would like to extend this thanks to our current Dean Professor Vergauwen, dear Philip, and to our head of department, Professor Bos, dear Jaap, the support of both the Faculty together with the Finance department and have made this position possible. Thank you. 
If I look back at my time at the Finance Department, then I have had the upmost pleasure and good fortune to work in a department that has allowed me a constructive balance between autonomy and freedom, and guidance and support. Dear Professor Eichholtz, dear Piet, and dear Professor Wolff, Dear Christian, thank you for your support at the beginning of my academic career following my PhD in Erasmus University Rotterdam to hire me and help my career blossom here in this beautiful city of Maastricht. I highly appreciate your support to allow me to grow and flourish here at the University; it is a very special place. Coming back to this city always gives me a warmth and energy that I feel very privileged to be able to be a part of.

The generosity, support and kindness throughout this University is something that I cherish. Dear Professor Bauer, dear Rob, in the early days here, we shared an office, and you were always happy to lend an ear at a time when I was juggling more balls than I could sometimes manage! I am glad I persevered. As did other roommates over the years, Aline, Frank, Nils, Nikos, and colleagues Jeroen, and Daniel and the list goes on. Likewise, many other close friends here today. Katharine, Louise all the way from England, Aicha and Nadia from Germany, I thank you for love and support over many years.

Dear Peter and Jean-Pierre for awakening my interest in finance following a degree in Economics and Econometrics in the UK. Dear Dennis, who suggested that I should even do a PhD and put me in touch with a potential supervisor; Kees.

Dear Professor Koedijk, dear Kees, who also had the faith very early in my career, and oftentimes brought me back to earth and make me focus on the present and what is possible within the academic industry. I appreciate your direct openness and confidence in me. Also for extending your network and allowing me to blossom, which as a female in finance, has not always been the easiest path. The challenge you set me was worth it. Thank you.

Dear Prof Statman, dear Meir, I thank you for your inspiration in the field of behavioural finance.

Dear Professor Lothian, Dear Jim, I thank you for your support and your endearing conversations over the years. 
Also to all my co-authors, and collaborators in particular Professor Graddy, Dearest Katy, Professor De Silva, Dear Dakshina, and Dear Roman, Dear Leonard. Also to Professors Michael Moses and Jianping Mei, with whom we have collaborated since 2008 with our global art databases and indices. Thank you Mike and JP.

Dear Professor Reneboog, Dear Luc, and those at the Finance Department of Tisem, UvT, thank you for the support in conducting research in the art markets, and for the possibility of continuing this with UvT with Tisem, through our joint PhD Marshall. Dear absent colleagues and friends, particularly those from Tilburg University and at TIAS School for Business and Society. Dear Ronald, Dirk and Frans.

Above all to all those from the Art world. Dear Anna, I value our friendship and always enjoy working with you; long may our friendship continue. Dear Anders, Dear Adriano, for the years of trusted support with the Annual Art Market Symposium, now in its $10^{\text {th }}$ year, and also with the Masterclasses in Art Finance, it's always been fun too, thank you.

Dear PhD Students, and former Students, Arian, Ayse, Marshall, Ylva, Florentine, and to my PhD Students in Maastricht, in particular, Leonard and Anouk, and recently following in the tracks, Marina, and Weiyan.

Also to my mother and recently deceased father, who initiated my interest in scholarship and academia. They taught me the values of critical thinking, integrity, and independent thought; and moreover opened my eyes to the world. I'm supported here today by my dearest cousin Mike, representative of many in the family who are unable to be with us today, thank you.

My deepest utmost thanks goes to my family, to my darling husband John, and my beautiful and intelligent daughters Jasmine \& Colette. Without whose continued support and love, I would not have had the time and space to dedicate myself to my work. I thank you for from the bottom of my heart for the times that it sadly took precedence.

My deepest respect and thanks to you all. 


\section{References}

References

References

References

Reterences

Reterences

Reterences

(1)

(1) 
Alchian, Armen (1953) “The meaning of utility measurement”, American Economic Review, 26-50.

Allais Maurice (I953) “Le Comportement de l'Homme Rationnel devant le Risque: Critique des Postulats et Axiomes de l'École Americaine”, Econometrica 2I, 503546.

Arrow, Kenneth, and Gerard Debreux (1954) "Existence of an equilibrium for a competitive economy" Econometrica, Vol. 22 No. 3 265-290.

Bailey, Martin J., Richard F. Muth, and Hugh O. Nourse (I963) "A regression method for real estate price index construction" Journal of the American Statistical Association 58, $933-942$.

Barberis, Nicholas (2013) "The psychology of tail events: Progress and challenges" American Economic Review, Iо3(3): 6ri-6i6.

Barberis, Nicholas, and Ming Huang (2008), "Stocks as lotteries: The implications of probability weighting for security prices" American Economic Review 98(5) 20662100.

Bernoulli, Daniel, (I738) "Specimen theoriae novae de mensura sortis", Commentarii Academiae Scientiarum Imperialis Petropolitanae 5. Translated by Louise Somer and reprinted as "Exposition of a new theory on the measurement of risk" I954, Econometrica, 22: 23-36.

Beulens, Nathalie and Victor Ginsburgh (2003) “Revisiting Baumol's art as floating crap game" European Economic Review. 7, I35I-I37I

Briggs, Rachael (20I5) “Normative theories of rational choice: Expected utility”, The Stanford Encyclopedia of Philosophy, Edward N. Zalta (ed.) URL $=<$ http://plato.stanford.edu/archives/win20I5/entries/rationality-normative-utility/>.

Baumol, William (1986) "Unnatural value: Or art investment as floating crap game” American Economic Review, 76(2), I0-I4.

Bollen, Nicholas (2007) "Mutual fund attributes and investor behavior". Journal of Financial and Quantitative Analysis, 42, I683-708. 
Borgers, Arian C. T., and Rachel A. J. Pownall (20I4) "Attitudes towards socially and environmentally responsible investment" Journal of Behavioral and Experimental Finance (1) 27-44.

Brounen, Dirk, Kees G. Koedijk, and Rachel A. J. Pownall (20I4) "Household financial planning and savings behavior", Forthcoming at Journal of International Money and Finance.

Campbell, Rachel. A. J., (2008a) “Art finance”, Chapter in Handbook of Finance, Edited by F. Fabozzi, Wiley Books, Volume I.

Campbell, Rachel A. J., (2008b) "Art as a financial investment", Journal of Alternative Investments, Spring Volume 10(4) p 64-81.

Campbell, Rachel A. J., (2008c) “Fine violins as an alternative investment: Stings attached? Pensions Volume 13, (1) \& (2) p 89-96.

Campbell, Rachel A. J. (2009) "Art risk", Chapter in Fine Art and High Finance. Edited by Clare McAndrew, Bloomberg.

Campbell, Rachel A. J., and Christian Weihenkamp (2007) "Credit default swaps: An application to the art market", Chapter in Credit Risk: Models, Derivatives, and Management. Edited by N. Wagner, Elsevier Books.

Case, Karl E., and Robert J. Shiller (I987) "Prices of single-family homes since I970: New indexes for four cities". New England Economic Review. September - October. 2-IO.

Citi GPS. Global perspectives and solutions (2015) Report.

Coase, Ronald (I960) “The problem of social cost". Journal of Law and Economics 3:I-44.

Damasio, Antonio (1994) Descartes Error: Emotion, Reason and the Human Brain. Avon Books, New Yok.

Deloitte (2015) Art and Finance Report, Luxembourg. 
Dempster, Anna (2013) "Risk and uncertainty in the art market". Bloomsbury Press.

De Roon, Frans, Kees G. Koedijk and Rachel A. J. Pownall (2008) "Emotional assets with emotional dividends", working paper.

Derwall, Jeroen, Nadja Guenster, Rob Bauer, and Kees G. Koedijk (2005) “The economic value of corporate eco-efficiency", Financial Analysts Journal, 6I(2) 5I-63.

De Silva, Dakshina G., and Rachel A. J. Pownall (2014) “Going green: Does it depend on gender, education or income?” Applied Economics, 46:5, 573-586.

De Silva, Dakshina G., Rachel A. J. Pownall, and L. Wolk (20I2) “Does the sun 'shine' on art prices?" Journal of Economic Behavior and Organization. 82 p I67-I78.

Edmans, Alex (20II) “Does the stock market fully value intangibles” Employee satisfaction and equity prices", Journal of Financial Economics, IOI, 62I-640.

Eichholtz, Piet, Nils Kok and John Quigley (20I0) “Doing well by doing good? Green office buildings" American Economic Review I00: 2492-2509

Ellsberg, Daniel (1961) “Risk, Ambiquity, and the Savage axioms”, The Quarterly Journal of Economics, 75(4) 643-669.

Epstein, Larry (1999) "A definition of uncertainty aversion", Tre Review of Economic Studies, Vol. 66, No. 3 579-608.

Fama, Eugune (I970) "Efficient capital markets: A review of theory and empirical work", Journal of Finance, Vol. 25 No. 2.383-417.

Frey, Bruno and Werner Pommerehne (1989) "Art investment: An inquiry”. Southern Economic Journal 56(2): 396-409.

Friedman, Milton (1962) Capitalism and Freedom. University of Chicago Press.

Friedman, Milton, and Leonard J. Savage (I948) “The utility analysis of choices involving risk". Journal of Political Economy, LVI, 279-304. 
Goetzman William (I993)"Accounting for taste: Art and financial markets over three centuries". American Economic Review 83(5): I370-1376.

Goetzman, William, Luc Reneboog, and Christophe Spanjaers (20II) "Art and money". American Economic Review. IоI(3): 222-226.

Graddy, Kathryn, John Hamilton and Rachel A. J Pownall (20I2) "Repeat sales indexes: Estimation without assuming that errors in asset returns are independently distributed" Journal of Real Estate Economics, 40 (I): 131-166.

Graddy, Kathryn, Lara Loewenstein, Jianping Mei, Michael Moses, and Rachel A. J Pownall (2013) "Anchoring or loss aversion? Empirical evidence from art auctions" CEPR Working paper.

Guiso, Luigi, Paola Sapienza, and Luigi Zingales, (2008), “Trusting the stock market", Journal of Finance, 63(6): 2557-2600.

Grammp, William D. (1989) Pricing the Priceless, Art, Artists and Economics. New York: Basic Books.

Griffith, Rachel, and Lars Nesheim (2013) "Hedonic Methods for Baskets of Goods", Economic Letters, I20, 284-287.

Hong, Harrison and Marcin Kacperczyk (2009) "The price of sin: The effects of social norms on markets", Journal of Financial Economics, 93(I) 15-36.

HRH Prince Charles (2003) The future of food. Address to the Washington Congress.

Jensen, Michael C. and William H. Meckling (I976). “Theory of the firm: Managerial behavior, agency costs and ownership structure". Journal of Financial Economics, 3(4), 305-360.

Kahneman, Daniel and Angus Deaton (2010) "High income imporves evaluation of life but not emotional well-being”, PNAS, Vol. I07, no. 38, I6489-16493.

Kahneman, Daniel and Amos Tversky (1974) Judgment Under Uncertainty: Heuristics and Biases, New York: Cambridge University Press. 
Kempf Alexander and Peer Osthoff (2008) “SRI funds: Normen est omen”. Journal of Business Finance and Accountings 35, I276-1294.

Knight, Frank H. (192I) Risk, Uncertainty, and Profit, Boston, MA.

Koedijk, Kees G., Rachel A. J. Pownall, and Meir Statman (20I4) “Aspirations for income and status, and risk attitudes", CEPR Working Paper.

Kortewijk, Arthus, Roman Kraeussl, and Patrick Verwijmeren (2015) "Does it pay to invest in art? A selection-corrected returns perspective". Forthcoming in the Review of Financial Studies.

Loewenstein, George F., Christopher K. Hsee, Elke U. Weber, and Ned Welch (200I) "Risk as feelings", Psychological Bulletin. Vol. I27. No.2, 267-236.

Lopes, Lola (1987). "Between hope and fear: The psychology of risk," Advances in Experimental Social Psychology. 20, 255-295.

Markowitz, Harry (I952) “Portfolio selection.” Journal of Finance 7:I, 77-99.

Mayer, Enrique, International Auction Records, New York: Mayer and Archer Fields.

McAndrew, Clare, (20I5) TEFAF Art Market Report.

Mei, Jianping, and Michael Moses, (2002) "Art as an Investment and the Underperformance of Masterpieces." American Economic Review, 92(5), I956-I668.

Paulo Vieito, J., Pownall, Rachel A. J., Armando Rocha and Fabio T. Rocha (20I5) “The neural behavior of investors', working paper.

Pownall, Rachel A. J., (2012) "Valuing the non-pecuniary benefits of assets using probability weighting functions", working paper.

Pownall, Rachel A. J., (2013) “The price of colour: Pricing colour intensity in Contemporary art auctions", working paper. 
Pownall, Rachel A. J., and L. Wolk (2013) "Experience and bidding behavior in internet auctions" European Economic Review, 6I, pI4-27.

Pownall, Rachel A. J., Stephen Satchell and Nandini Srivastava (2012) "A random walk through Mayfair: Dynamic models of UK art market prices and their dependence on UK equity prices" forthcoming.

Ransome William, and Charles Sampford (2013) Ethics and Socially Responsible Investment. Ashgate Publishing.

Reitlinger, Gerald (I96I) "The economics of taste: The rise and fall of picture prices I760-I960". London: Barrie and Rockliff.

Rengers, Merijn, and Olav Velthuis (2002) "Determinants of prices for contemporary art in Amsterdam art galleries I992-1998" Jounral of Cultural Economics, 26(2) I-28.

Rottenstreich, Yuval, and Christopher K. Hsee (200I) "Money, kisses, and electric shocks: On the affective psychology of risk". Psychological Science, I2(3), I85-190.

Rush, Richard (I96I) “Art as an investment”. New York: Bonanza.

Samuelson, Marta (2015) “Managing with soft metrics”, Harvard Business Review article November.

Savage, Leonard J., (I972) The Foundations of Statistics, 2nd edition, New York: Dover Publications, Inc.

Statman, Meir and Dennis Glushkov (2009) “The wages of social responsibility”. Financial Analysts Journal 65, 33-46.

Statman, Meir (20II) “What investors really want” McGraw Hill

Stein, John Picard (I977) “The monetary appreciation of paintings”. Journal of Political Economy", 85(5): IO2I-I035.

Terzi, Ayse, Kees G. Koedijk, Charles N. Noussair, and Rachel A. J. Pownall (2015) “Reference point formation”, CEPR Working Paper. 
Towse, Ruth (20II) Handbook of Cultural Economics $2^{\text {nd }}$ Edition.

Tversky Amos and Daniel Kahneman (1992) "Advances in 'Prospect Theory':

Cumulative representation of utility", Journal of Risk and Uncertainty, 5:297-323.

Von Neumann, John and Oskar Morgenstern (I944), "Theory of Games and Economic Behavior", Princeton: Princeton University Press.

World Bank, (I997) "Expanding the Measure of Wealth: Indicators of Environmentally Sustainable Development”, Washington, D.C. 


\section{Colophon}

copyright

Rachel A. J. Pownall

graphic design and print

PrismaPrint, Tilburg University 
